4

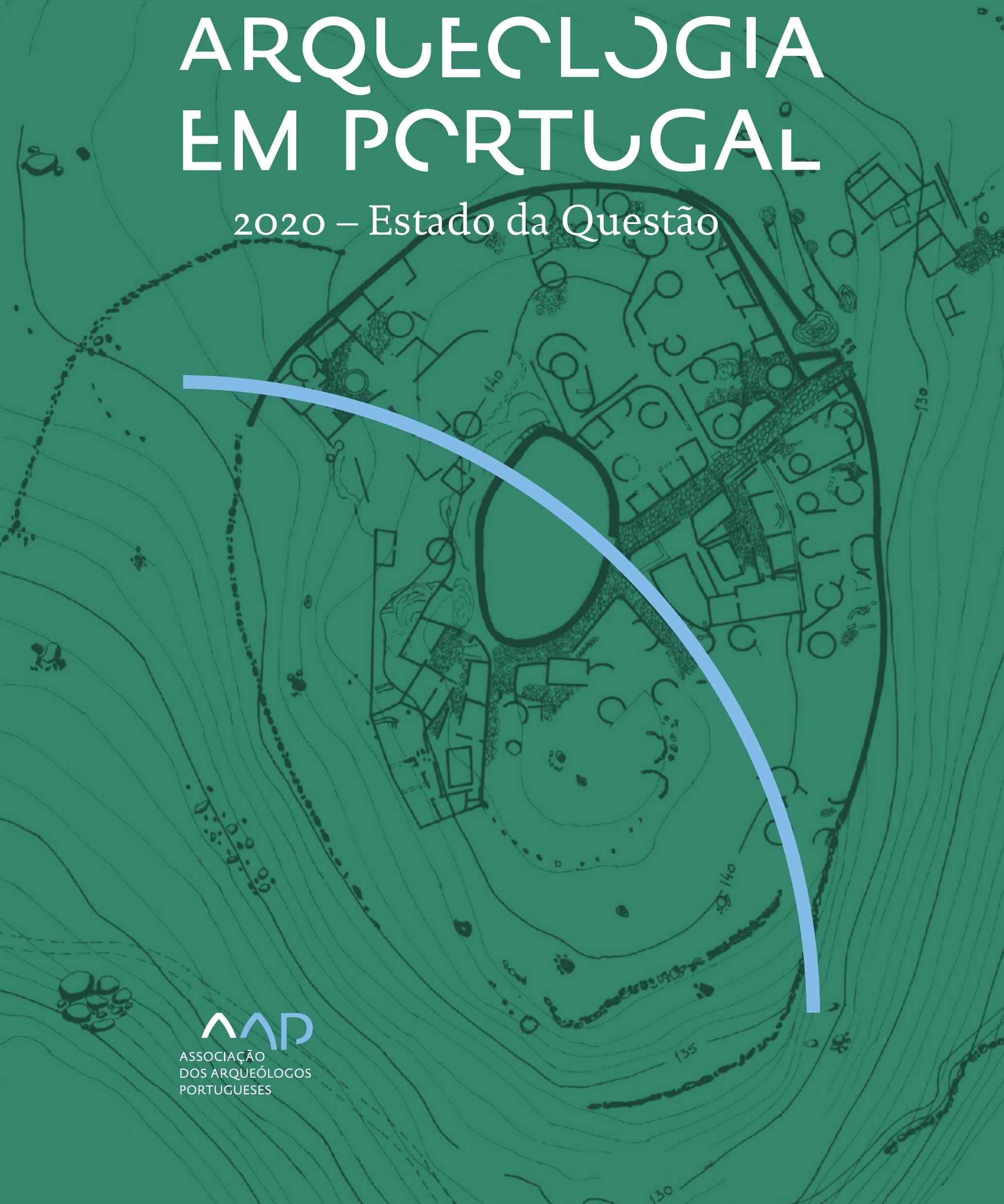


Coordenação editorial: José Morais Arnaud, César Neves e Andrea Martins Design gráfico: Flatland Design

AAP - ISBN: 978-972-9451-89-8

CITCEM - ISBN: 978-989-8970-25-1

Associação dos Arqueólogos Portugueses e CITCEM

Lisboa, 2020

O conteúdo dos artigos é da inteira responsabilidade dos autores. Sendo assim a Associação dos Arqueólogos Portugueses declina qualquer responsabilidade por eventuais equívocos ou questões de ordem ética e legal.

Desenho de capa:

Planta do castro de Monte Mozinho (Museu Municipal de Penafiel).

\section{$\hat{\wedge} \mathrm{P}$}

DOS ARQUEÓLOGOS PORTUGUESES

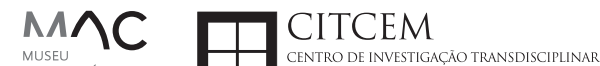
MUSEU
ARQUELLÓGICO
DO CARMO
U.PORTO

FLUP FACULDADE DE LETRAS
UNIVERSIDADE DO PORTO

Apoio

EC para a Ciência 


\section{Índice}

15 Prefácio

José Morais Arnaud

\section{Historiografia e Teoria}

17 Território, comunidade, memória e emoção: a contribuição da história da arqueologia (algumas primeiras e breves reflexões)

Ana Cristina Martins

25 Como descolonizar a arqueologia portuguesa?

Rui Gomes Coelho

41 Arqueologia e Modernidade: uma revisitação pessoal e breve de alguns aspetos da obra homónima de Julian Thomas de 2004

Vítor Oliveira Jorge

57 Dados para a História das Mulheres na Arqueologia portuguesa, dos finais do século XIX aos inícios do século XX: números, nomes e tabelas

Filipa Dimas / Mariana Diniz

73 Retractos da arqueologia portuguesa na imprensa: (in)visibilidades no feminino

Catarina Costeira / Elsa Luís

85 Arqueologia e Arqueólogos no Norte de Portugal Jacinta Bugalhão

101 Vieira Guimarães (1864-1939) e a arqueologia em Tomar: uma abordagem sobre o território e as gentes

João Amendoeira Peixoto / Ana Cristina Martins

115 Os memoráveis? A arqueologia algarvia na imprensa nacional e regional na presente centúria (2001-2019): características, visões do(s) passado(s) e a arqueologia

enquanto marca

Frederico Agosto / João Silva

129 A Evolução da Arqueologia Urbana e a Valorização Patrimonial no Barlavento Algarvio: Os casos de Portimão e Silves

Artur Mateus / Diogo Varandas / Rafael Boavida

\section{Gestão, Valorização e Salvaguarda do Património}

145 O Caderno Reivindicativo e as condições de trabalho em Arqueologia Miguel Rocha / Liliana Matias Carvalho / Regis Barbosa / Mauro Correia / Sara Simões / Jacinta Bugalhão / Sara Brito / Liliana Veríssimo Carvalho / Richard Peace / Pedro Peça / Cézer Santos

155 Os Estudos de Impacte Patrimonial como elemento para uma estratégia sustentável de minimização de impactes no âmbito de reconversões agrícolas Tiago do Pereiro

165 Salvaguarda de Património arqueológico em operações florestais: gestão e sensibilização Filipa Bragança / Gertrudes Zambujo / Sandra Lourenço / Belém Paiva / Carlos Banha / Frederico Tatá Regala / Helena Moura / Jacinta Bugalhão / João Marques / José Correia / Pedro Faria / Samuel Melro

179 Os valores do Património: uma investigação sobre os Sítios Pré-históricos de Arte Rupestre do Vale do Rio Côa e de Siega Verde José Paulo Francisco 
189 Conjugando recursos arqueológicos e naturais para potenciar as visitas ao Geoparque Litoral de Viana do Castelo (Noroeste de Portugal)

Hugo A. Sampaio / Ana M.S. Bettencourt / Susana Marinho / Ricardo Carvalhido

203 Áreas de Potencial Arqueológico na Região do Médio Tejo: Modelo Espacial Preditivo Rita Ferreira Anastácio / Ana Filipa Martins / Luiz Oosterbeek

223 Património Arqueológico e Gestão Territorial: O contributo da Arqueologia para a revisão do PDM de Avis

Ana Cristina Ribeiro

237 A coleção arqueológica do extinto Museu Municipal do Porto - Origens, Percursos e Estudos

Sónia Couto

251 Valpaços - uma nova carta arqueológica

Pedro Pereira / Maria de Fátima Casares Machado

263 Arqueologia na Cidade de Peniche

Adriano Constantino / Luís Rendeiro

273 Arqueologia Urbana: a cidade de Lagos como caso de Estudo Cátia Neto

285 Estratégias de promoção do património cultural subaquático nos Açores. O caso da ilha do Faial

José Luís Neto / José Bettencourt / Luís Borges / Pedro Parreira

297 Carta Arqueológica da Cidade Velha: Uma primeira abordagem

Jaylson Monteiro / Nireide Tavares / Sara da Veiga / Claudino Ramos / Edson Brito /

Carlos Carvalho / Francisco Moreira / Adalberto Tavares

311 Antropologia Virtual: novas metodologias para a análise morfológica e funcional Ricardo Miguel Godinho / Célia Gonçalves

\section{Didáctica da Arqueologia}

327 Como os projetos de Arqueologia podem contribuir para uma comunidade culturalmente mais consciente Alexandra Figueiredo / Claúdio Monteiro / Adolfo Silveira / Ricardo Lopes

337 Educação Patrimonial - Um cidadão esclarecido é um cidadão ativo! Ana Paula Almeida

351 A aproximação da Arqueologia à sala de aula: um caso de estudo no $3^{\circ}$ ciclo do Ensino Básico Luís Serrão Gil

363 Arqueologia 3.o - Pensar e comunicar a Arqueologia para um futuro sustentável Mónica Rolo

377 “Conversa de Arqueólogos" - Divulgar a Arqueologia em tempos de Pandemia Diogo Teixeira Dias

389 Escola Profissional de Arqueologia: desafios e oportunidades Susana Nunes / Dulcineia Pinto / Júlia Silva / Ana Mascarenhas

399 Os Museus de Arqueologia e os Jovens: a oferta educativa para o público adolescente Beatriz Correia Barata / Leonor Medeiros

411 O museu universitário como mediador entre a ciência e a sociedade: o exemplo da secção de arqueologia no Museu de História Natural e da Ciência da Universidade do Porto (MHNC-UP)

Rita Gaspar 
421 Museu de Lanifícios: Real Fábrica de Panos. Atividades no âmbito da Arqueologia Beatriz Correia Barata / Rita Salvado

427 Arqueologia Pública e o caso da localidade da Mata (Torres Novas) Cláudia Manso / Ana Rita Ferreira / Cristiana Ferreira / Vanessa Cardoso Antunes

431 Do sítio arqueológico ao museu: um percurso (também) didático Lídia Fernandes

447 Estão todos convidados para a Festa! E para dançar também... O projecto do Serviço Educativo do Museu Arqueológico do Carmo na $5^{\underline{a}}$ Edição da Festa da Arqueologia Rita Pires dos Santos

459 O “Clã de Carenque”, um projeto didático de arqueologia Eduardo Gonzalez Rocha

469 Mediação cultural: peixe que puxa carroça nas Ruínas Romanas de Troia Inês Vaz Pinto / Ana Patrícia Magalhães / Patrícia Brum / Filipa Santos

481 Didática Arqueológica, experiências do Projeto Mértola Vila Museu Maria de Fátima Palma / Clara Rodrigues / Susana Gómez / Lígia Rafael

\section{Arte Rupestre}

497 Os inventários de arte rupestre em Portugal Mila Simões de Abreu

513 O projeto FIRST-ART - conservação, documentação e gestão das primeiras manifestações de arte rupestre no Sudoeste da Península Ibérica: as grutas do Escoural e Maltravieso Sara Garcês / Hipólito Collado / José Julio García Arranz / Luiz Oosterbeek / António Carlos Silva / Pierluigi Rosina / Hugo Gomes / Anabela Borralheiro Pereira / George Nash / Esmeralda Gomes / Nelson Almeida / Carlos Carpetudo

523 Trabalhos de documentação de arte paleolítica realizados no âmbito do projeto PalæoCôa André Tomás Santos / António Fernando Barbosa / Luís Luís / Marcelo Silvestre / Thierry Aubry

537 Imagens fantasmagóricas, silhuetas elusivas: as figuras humanas na arte do Paleolítico Superior da região do Côa Mário Reis

$55^{1}$ Os motivos zoomórficos representados nas placas de tear de Vila Nova de São Pedro (Azambuja, Portugal) Andrea Martins / César Neves / José M. Arnaud / Mariana Diniz

571 Arte Rupestre do Monte de Góios (Lanhelas, Caminha). Síntese dos resultados dos trabalhos efectuados em 2007-2009 Mário Varela Gomes

599 Gravuras rupestres de barquiformes no Monte de S. Romão, Guimarães, Noroeste de Portugal Daniela Cardoso

613 Círculos segmentados gravados na Bacia do Rio Lima (Noroeste de Portugal): contributos para o seu estudo Diogo Marinho / Ana M.S. Bettencourt / Hugo Aluai Sampaio

631 Equídeos gravados no curso inferior do Rio Mouro, Monção (NW Portugal). Análise preliminar Coutinho, L.M. / Bettencourt, A.M.S / Sampaio, Hugo A.S

645 Paletas na Arte Rupestre do Noroeste de Portugal. Inventário preliminar Bruna Sousa Afonso / Ana M. S. Bettencourt / Hugo A. Sampaio 


\section{Pré-História}

661 O projeto Miño/Minho: balanço de quatro anos de trabalhos arqueológicos Sérgio Monteiro-Rodrigues / João Pedro Cunha-Ribeiro / Eduardo Méndez-Quintas / Carlos Ferreira / Pedro Xavier / José Meireles / Alberto Gomes / Manuel Santonja / Alfredo Pérez-González

677 A ocupação paleolítica da margem esquerda do Baixo Minho: a indústria lítica do sítio de Pedreiras 2 (Monção, Portugal) e a sua integração no contexto regional Carlos Ferreira / João Pedro Cunha-Ribeiro / Sérgio Monteiro-Rodrigues / Eduardo Méndez-Quintas / Pedro Xavier / José Meireles / Alberto Gomes / Manuel Santonja / Alfredo Pérez-González

693 O sítio acheulense do Plistocénico médio da Gruta da Aroeira Joan Daura / Montserrat Sanz / Filipa Rodrigues / Pedro Souto / João Zilhão

703 As sociedades neandertais no Barlavento algarvio: modelos preditivos com recurso aos SIG

Daniela Maio

715 A utilização de quartzo durante o Paleolítico Superior no território dos vales dos rios Vouga e Côa

Cristina Gameiro / Thierry Aubry / Bárbara Costa / Sérgio Gomes / Luís Luís / Carmen Manzano / André Tomás Santos

733 Uma perspetiva diacrónica da ocupação do concheiro do Cabeço da Amoreira (Muge, Portugal) a partir da tecnologia lítica Joana Belmiro / João Cascalheira / Célia Gonçalves

745 Novos dados sobre a Pré-história Antiga no concelho de Palmela. A intervenção arqueológica no sítio do Poceirão I

Michelle Teixeira Santos

757 Problemas em torno de Datas Absolutas Pré-Históricas no Norte do Alentejo Jorge de Oliveira

771 Povoamento pré-histórico nas áreas montanhosas do NO de Portugal: o Abrigo 1 de Vale de Cerdeira Pedro Xavier / José Meireles / Carlos Alves

783 Apreciação do povoamento do Neolítico Inicial na Baixa Bacia do Douro. A Lavra I (Serra da Aboboreira) como caso de estudo Maria de Jesus Sanches

797 O Processo de Neolitização na Plataforma do Mondego: os dados do Sector C do Outeiro dos Castelos de Beijós (Carregal do Sal)

João Carlos de Senna-Martinez / José Manuel Quintã Ventura / Andreia Carvalho / Cíntia Maurício

823 Novos trabalhos na Lapa da Bugalheira (Almonda, Torres Novas) Filipa Rodrigues / Pedro Souto / Artur Ferreira / Alexandre Varanda / Luís Gomes / Helena Gomes / João Zilhão

837 A pedra polida e afeiçoada do sítio do Neolítico médio da Moita do Ourives (Benavente, Portugal)

César Neves

857 Casal do Outeiro (Encarnação, Mafra): novos contributos para o conhecimento do povoamento do Neolítico final na Península de Lisboa.

Cátia Delicado / Carlos Maneira e Costa / Marta Miranda / Ana Catarina Sousa

873 Stresse infantil, morbilidade e mortalidade no sítio arqueológico do Neolítico Final/ Calcolítico ( $4^{\circ}$ e $3^{\circ}$ milénio a.C.) do Monte do Carrascal 2 (Ferreira do Alentejo, Beja) Liliana Matias de Carvalho / Sofia N. Wasterlain 
885 Come together: O Conjunto Megalítico das Motas (Monção, Viana do Castelo) e as expressões Campaniformes do Alto Minho Ana Catarina Basílio / Rui Ramos

899 Trabalhos arqueológicos no sítio Calcolítico da Pedreira do Poio Carla Magalhães / João Muralha / Mário Reis / António Batarda Fernandes

913 O sítio arqueológico de Castanheiro do Vento. Da arquitectura do sítio à arquitectura de um território João Muralha Cardoso

925 Estudo zooarqueológico das faunas do Calcolítico final de Vila Nova de São Pedro (Azambuja, Portugal): Campanhas de 2017 e 2018 Cleia Detry / Ana Catarina Francisco / Mariana Diniz / Andrea Martins / César Neves / José Morais Arnaud

943 As faunas depositadas no Museu Arqueológico do Carmo provenientes de Vila Nova de São Pedro (Azambuja): as campanhas de 1937 a 1967 Ana Catarina Francisco / Cleia Detry / César Neves / Andrea Martins / Mariana Diniz / José Morais Arnaud

959 Análise funcional de material lítico em sílex do castro de Vila Nova de S. Pedro (Azambuja, Portugal): uma primeira abordagem Rafael Lima

971 O recinto da Folha do Ouro 1 (Serpa) no contexto dos recintos de fossos calcolíticos alentejanos

António Carlos Valera / Tiago do Pereiro / Pedro Valério / António M. Monge Soares

\section{Proto-História}

987 Produção de sal marinho na Idade do Bronze do noroeste Português. Alguns dados para uma reflexão

Ana M. S. Bettencourt / Sara Luz / Nuno Oliveira / Pedro P. Simões / Maria Isabel C. Alves / Emílio Abad-Vidal

1001 A estátua-menir do Pedrão ou de São Bartolomeu do Mar (Esposende, noroeste de Portugal) no contexto arqueológico da fachada costeira de entre os rios Neiva e Cávado Ana M. S. Bettencourt / Manuel Santos-Estévez / Pedro Pimenta Simões / Luís Gonçalves

1015 O Castro do Muro (Vandoma/Baltar, Paredes) - notas para uma biografia de ocupação da Idade do Bronze à Idade Média

Maria Antónia D. Silva / Ana M. S. Bettencourt / António Manuel S. P. Silva / Natália Félix

1031 Do Bronze Final à Idade Média - continuidades e hiatos na ocupação de Povoados em Oliveira de Azeméis João Tiago Tavares / Adriaan de Man

1041 As faunas do final da Idade do Bronze no Sul de Portugal: leituras desde o Outeiro do Circo (Beja)

Nelson J. Almeida / Íris Dias / Cleia Detry / Eduardo Porfírio / Miguel Serra

1055 A Espada do Monte das Oliveiras (Serpa) - uma arma do Bronze Pleno do Sudoeste Rui M. G. Monge Soares / Pedro Valério / Mariana Nabais / António M. Monge Soares

1065 São Julião da Branca (Albergaria-a-Velha) - Investigação e valorização de um povoado do Bronze Final

António Manuel S. P. Silva / Paulo A. P. Lemos / Sara Almeida e Silva / Edite Martins de Sá

1083 Do castro de S. João ao Mosteiro de Santa Clara: notícia de uma intervenção arqueológica, em Vila do Conde Rui Pinheiro 
1095 O castro de Ovil (Espinho), um quarto de século de investigação - resultados e questões em aberto

Jorge Fernando Salvador / António Manuel S. P. Silva

1111 O Castro de Salreu (Estarreja), um povoado proto-histórico no litoral do Entre Douro e Vouga

Sara Almeida e Silva / António Manuel S. P. Silva / Paulo A. P. Lemos / Edite Martins de Sá

1127 Castro de Nossa Senhora das Necessidades (Sernancelhe): uma primeira análise artefactual Telma Susana O. Ribeiro

${ }_{1141}$ A cividade de Bagunte. O estado atual da investigação Pedro Brochado de Almeida

1153 Zoomorfos na cerâmica da Idade do Ferro no NW Peninsular: inventário, cronologias e significado Nuno Oliveira / Cristina Seoane

1163 Vasos gregos em Portugal: diferentes maneiras de contar a história do intercâmbio cultural na Idade do Ferro

Daniela Ferreira

1175 Os exotica da necrópole da Idade do Ferro do Olival do Senhor dos Mártires (Alcácer do Sal) no seu contexto regional

Francisco B. Gomes

\section{Antiguidade Clássica e Tardia}

1191 O uso de madeira como combustível no sítio da Quinta de Crestelos (Baixo Sabor): da Idade do Ferro à Romanização Filipe Vaz / João Tereso / Sérgio Simões Pereira / José Sastre / Javier Larrazabal Galarza / Susana Cosme / José António Pereira / Israel Espi

1207 Cultivos de Época Romana no Baixo Sabor: continuidade em tempos de mudança? João Pedro Tereso / Sérgio Simões Pereira / Filipe Santos / Luís Seabra / Filipe Vaz

1221 A casa romana na Hispânia: aplicação dos modelos itálicos nas províncias ibéricas Fernanda Magalhães / Diego Machado / Manuela Martins

1235 As pinturas murais romanas da Rua General Sousa Machado, n. ${ }^{5}$ 1, Chaves José Carvalho

1243 Trás do Castelo (Vale de Mir, Pegarinhos, Alijó) - Uma exploração agrícola romana do Douro

Tony Silvino / Pedro Pereira

1255 A sequência de ocupação no quadrante sudeste de Bracara Augusta: as transformações de uma unidade doméstica Lara Fernandes / Manuela Martins

1263 Os Mosaicos com decoração geométrica e geométrico-vegetalista dos sítios arqueológicos da área do Conuentus Bracaraugustanus. Novas abordagens quanto à conservação, restauro, decoração e datação Maria de Fátima Abraços / Licínia Wrench

1277 “Casa Romana” do Castro de São Domingos (Cristelos, Lousada): Escavação, Estudo e Musealização Paulo André de P. Lemos

1291 A arqueobotânica no Castro de Guifões (Matosinhos, Noroeste de Portugal): O primeiro estudo carpológico

Luís Seabra / Andreia Arezes / Catarina Magalhães / José Varela / João Pedro Tereso 
1305 Um Horreum Augustano na Foz do Douro (Monte do Castelo de Gaia, Vila Nova de Gaia) Rui Ramos

1311 Ponderais romanos na Lusitânia: padrões, formas, materiais e contextos de utilização Diego Barrios Rodríguez

1323 Um almofariz centro-itálico na foz do Mondego

Marco Penajoia

1335 Estruturas romanas de Carnide - Lisboa Luísa Batalha / Mário Monteiro / Guilherme Cardoso

1347 O contexto funerário do sector da "necrópole NO" da Rua das Portas de S. Antão (Lisboa): o espaço, os artefactos, os indivíduos e a sua interconectividade na interpretação do passado Sílvia Loja, José Carlos Quaresma, Nelson Cabaço, Marina Lourenço, Sílvia Casimiro, Rodrigo Banha da Silva, Francisca Alves-Cardoso

${ }_{1361}$ Povoamento em época Romana na Amadora - resultados de um projeto pluridisciplinar Gisela Encarnação / Vanessa Dias

1371 A Arquitectura Residencial em Mirobriga (Santiago do Cacém): contributo a partir de um estudo de caso Filipe Sousa / Catarina Felício

${ }_{1385}$ O fim do ciclo. Saneamento e gestão de resíduos nos edifícios termais de Mirobriga (Santiago do Cacém)

Catarina Felício / Filipe Sousa

1399 Balsa, Topografia e Urbanismo de uma Cidade Portuária Vítor Silva Dias / João Pedro Bernardes / Celso Candeias / Cristina Tété Garcia

1413 No Largo das Mouras Velhas em Faro (2017): novas evidências da necrópole norte de Ossonoba e da sua ocupação medieval Ricardo Costeira da Silva / Paulo Botelho / Fernando Santos / Liliana Nunes

1429 Instrumentos de pesca recuperados numa fábrica de salga em Ossonoba (Faro) Inês Rasteiro / Ricardo Costeira da Silva / Paulo Botelho

1439 A Necrópole Romana do Eirô, Duas Igrejas (Penafiel): intervenção arqueológica de 2016 Laura Sousa / Teresa Soeiro

1457 Ritual, descarte ou afetividade? A presença de Canis lupus familiaris na Necrópole Noroeste de Olisipo (Lisboa)

Beatriz Calapez Santos / Sofia Simões Pereira / Rodrigo Banha da Silva / Sílvia Casimiro / Cleia Detry / Francisca Alves Cardoso

1467 Dinâmicas económicas em Bracara na Antiguidade Tardia Diego Machado / Manuela Martins / Fernanda Magalhães / Natália Botica

1479 Cerâmicas e Vidros da Antiguidade Tardia do Edifício sob a Igreja do Bom Jesus (Vila Nova de Gaia) Joaquim Filipe Ramos

1493 Novos contributos para a topografia histórica de Mértola no período romano e na Antiguidade Tardia Virgílio Lopes

\section{8. Época Medieval}

1511 Cerâmicas islâmicas no Garb setentrional "português": algumas evidências e incógnitas Constança dos Santos / Helena Catarino / Susana Gómez / Maria José Gonçalves / Isabel Inácio / Gonçalo Lopes / Jacinta Bugalhão / Sandra Cavaco / Jaquelina Covaneiro / Isabel Cristina Fernandes / Ana Sofia Gomes 
1525 Contributo para o conhecimento da cosmética islâmica, em Silves, durante a Idade Média Rosa Varela Gomes

1537 Yábura e o seu território - uma análise histórico-arqueológica de Évora entre os séculos VIII-XII José Rui Santos

1547 A encosta sul do Castelo de Palmela - resultados preliminares da escavação arqueológica Luís Filipe Pereira / Michelle Teixeira Santos

1559 A igreja de São Lourenço (Mouraria, Lisboa): um conjunto de silos e de cerâmica medieval islâmica

Andreia Filipa Moreira Rodrigues

1571 O registo material de movimentações populacionais no Médio Tejo, durante os séculos XII-XIII. Dois casos de "sunken featured buildings", nos concelhos de Cartaxo e Torres Novas Marco Liberato / Helena Santos / Nuno Santos

1585 O nordeste transmontano nos alvores da Idade média. Notas para reflexão Ana Maria da Costa Oliveira

1601 Sepulturas escavadas na rocha do Norte de Portugal e do Vale do Douro: primeiros resultados do Projecto SER-NPVD

Mário Jorge Barroca / César Guedes / Andreia Arezes / Ana Maria Oliveira

1619 "Portucalem Castrum Novum" entre o Mediterrâneo e o Atlântico: o estudo dos materiais cerâmicos alto-medievais do arqueossítio da rua de D. Hugo, nํ. 5 (Porto) João Luís Veloso

1627 A Alta Idade Média na fronteira de Lafões: notas preliminares sobre a Arqueologia no Concelho de Vouzela

Manuel Luís Real / Catarina Tente

1641 Um conjunto cerâmico medieval fora de portas: um breve testemunho aveirense Susana Temudo

${ }_{1651}$ Os Lóios do Porto: uma perspetiva integrada no panorama funerário da Baixa Idade Média à Época Moderna em meios urbanos em Portugal

Ana Lema Seabra

1659 O Caminho Português Interior de Santiago como eixo viário na Idade Média Pedro Azevedo

1665 Morfologia Urbana: Um exercício em torno do Castelo de Ourém André Donas-Botto / Jaqueline Pereira

1677 Intervenção arqueológica na Rua Marquês de Pombal/Largo do Espírito Santo (Bucelas, Loures)

Florbela Estêvão / Nathalie Antunes-Ferreira / Dário Ramos Neves / Inês Lisboa

1691 O Cemitério Medieval do Poço do Borratém e a espacialidade funerária na cidade de Lisboa Inês Belém / Vanessa Filipe / Vasco Noronha Vieira / Sónia Ferro / Rodrigo Banha da Silva

1705 Um Espaço Funerário Conventual do séc. XV em Lisboa: o caso do Convento de São Domingos da Cidade Sérgio Pedroso / Sílvia Casimiro / Rodrigo Banha da Silva / Francisca Alves Cardoso

\section{9. Época Moderna e Contemporânea}

1721 Arqueologia Moderna em Portugal: algumas reflexões críticas em torno da quantificação de conjuntos cerâmicos e suas inferências históricas e antropológicas Rodrigo Banha da Silva / André Bargão / Sara da Cruz Ferreira

1733 Faianças de dois contextos entre os finais do século XVI e XVIII do Palácio dos Condes de Penafiel, Lisboa

Martim Lopes / Tomás Mesquita 
1747 Um perfil de consumo do século XVIII na foz do Tejo: O caso do Mercado da Ribeira, Lisboa Sara da Cruz Ferreira / Rodrigo Banha da Silva / André Bargão

1761 Os Cachimbos dos Séculos XVII e XVIII do Palácio Mesquitela e Convento dos Inglesinhos (Lisboa)

Inês Simão / Marina Pinto / João Pimenta / Sara da Cruz Ferreira / André Bargão / Rodrigo Banha da Silva

1775 "Tomar os fumos da erua que chamão em Portugal erua sancta». Estudo de Cachimbos provenientes da Rua do Terreiro do Trigo, Lisboa

Miguel Martins de Sousa / José Pedro Henriques / Vanessa Galiza Filipe

1787 Cachimbos de Barro Caulínitico da Sé da Cidade Velha (República de Cabo Verde)

Rodrigo Banha da Silva / João Pimenta / Clementino Amaro

1801 Algumas considerações sobre espólio não cerâmico recuperado no Largo de Jesus (Lisboa) Carlos Boavida

1815 Adereços de vidro, dos séculos XVI-XVIII, procedentes do antigo Convento de Santana de Lisboa (anéis, braceletes e contas)

Joana Gonçalves / Rosa Varela Gomes / Mário Varela Gomes

1837 Da ostentação, luxo e poder à simplicidade do uso quotidiano: arqueologia e simbologia de joias e adornos da Idade Moderna Portuguesa Jéssica Iglésias

1849 Os amuletos em Portugal - dos objetos às superstições: o coral vermelho Alexandra Vieira

1865 Cerâmicas de Vila Franca de Xira nos séculos XV e XVI Eva Pires

1879 «Não passa por teu o que me pertence». Marcas de individualização associadas a faianças do Convento de Nossa Senhora de Aracoeli, Alcácer do Sal Catarina Parreira / Íris Fragoso / Miguel Martins de Sousa

1891 Cerâmica de Leiria: alguns focos de produção

Jaqueline Pereira / André Donas-Botto

1901 Os Fornos na Rua da Biquinha, em Óbidos Hugo Silva / Filipe Oliveira

1909 A casa de Pêro Fernandes, contador dos contos de D. Manuel I: o sítio arqueológico da Silha do Alferes, Seixal (século XVI) Mariana Nunes Ferreira

1921 O Alto da Vigia (Sintra) e a vigilância e defesa da costa Alexandre Gonçalves / Sandra Santos

1937 O contexto da torre sineira da Igreja de Santa Maria de Loures Paulo Calaveira / Martim Lopes

1949 A Necrópole do Hospital Militar do Castelo de São Jorge e as práticas funerárias na Lisboa de Época Moderna Susana Henriques / Liliana Matias de Carvalho / Ana Amarante / Sofia N. Wasterlain

1963 SAND - Sarilhos Grandes Entre dois Mundos: o adro da Igreja e a Paleobiologia dos ossos humanos recuperados

Paula Alves Pereira / Roger Lee Jesus / Bruno M. Magalhães

1975 Expansão urbana da vila de Cascais no século XVII e XVIII: a intervenção arqueológica na Rua da Vitória no 15 a 17

Tiago Pereira / Vanessa Filipe

1987 Novos dados para o conhecimento do Urbanismo de Faro em época Moderna Ana Rosa 
1995 Um exemplo de Arqueologia Urbana em Alcoutim: o Antigo Edifício dos CTT Marco Fernandes / Marta Dias / Alexandra Gradim / Virgílio Lopes / Susana Gómez Martínez

2007 Palácio dos Ferrazes (Rua das Flores/Rua da Vitória, Porto): a cocheira de Domingos Oliveira Maia

Francisco Raimundo

2021 As muitas vidas de um edifício urbano: História, Arqueologia e Antropologia no antigo Recreatório Paroquial de Penafiel Helena Bernardo / Jorge Sampaio / Marta Borges

2035 O convento de Nossa Senhora da Esperança de Ponta Delgada: o contributo da arqueologia para o conhecimento de um monumento identitário João Gonçalves Araújo / N’Zinga Oliveira

2047 Arqueologia na ilha do Corvo... em busca da capela de Nossa Senhora do Rosário Tânia Manuel Casimiro / José Luís Neto / Luís Borges / Pedro Parreira

2059 Perdidos à vista da Costa. Trabalhos arqueológicos subaquáticos na Barra do Tejo Jorge Freire / José Bettencourt / Augusto Salgado

2071 Arqueologia marítima em Cabo Verde: enquadramento e primeiros resultados do projecto CONCHA

José Bettencourt / Adilson Dias / Carlos Lima / Christelle Chouzenoux / Cristóvão Fonseca / Dúnia Pereira / Gonçalo Lopes / Inês Coelho / Jaylson Monteiro / José Lima / Maria Eugénia Alves / Patrícia Carvalho / Tiago Silva

2085 Trabalhos arqueológicos na Cidade Velha (Ribeira Grande de Santiago, Cabo Verde): reflexões sobre um projecto de investigação e divulgação patrimonial André Teixeira / Jaylson Monteiro / Mariana Mateus / Nireide Tavares / Cristovão Fonseca / Gonçalo C. Lopes / Joana Bento Torres / Dúnia Pereira / André Bargão / Aurélie Mayer / Bruno Zélie / Carlos Lima / Christelle Chouzenoux / Inês Henriques / Inês Pinto Coelho / José Lima / Patrícia Carvalho / Tiago Silva

2103 A antiga fortificação de Quelba / Khor Kalba (E.A.U.). Resultados de quatro campanhas de escavações, problemáticas e perspectivas futuras Rui Carita / Rosa Varela Gomes / Mário Varela Gomes / Kamyar Kamyad

2123 Colónias para homens novos: arqueologia da colonização agrária fascista no noroeste ibérico Xurxo Ayán Vila / José Mạ . Señorán Martín 


\title{
CERÂMICAS DE VILA FRANCA DE XIRA NOS SÉCULOS XV E XVI
}

Eva Pires ${ }^{1}$

\begin{abstract}
RESUMO
A intervenção arqueológica efectuada no sítio do Ateneu Artístico Vilafranquense em 2007, no âmbito da arqueologia preventiva, revelou dados acerca do aglomerado urbano de Vila Franca de Xira durante a Baixa Idade Média e início da Idade Moderna.

O estudo realizado sobre a totalidade do espólio proveniente desta intervenção, constituído por um conjunto de cerâmicas, faunas, vidros, metais e líticos, permitiu inferir o cariz doméstico deste contexto composto por restos de consumo da população urbana. Apresentam-se os resultados finais da análise dos materiais cerâmicos que correspondem a um total de 492 peças identificáveis (NMI), associadas maioritariamente aos séculos XV e XVI. Palavras-chave: Arqueologia Urbana, Cerâmica, Idade Moderna, Séculos XV-XVI, Vila Franca de Xira.
\end{abstract}

\begin{abstract}
The archaeological intervention in the Ateneu Artístico Vilafranquense site in 2007, in the context of preventive archaeology, revealed data about the urban center of Vila Franca de Xira during the Late Middle Ages and Early Modern Age.

The study of the entire set of materials from this intervention, made up of ceramics, faunal remains, glass, metals and lithic materials, allowed us to infer the domestic nature of this context comprised of the town population's consumption remains. We present the final results of the ceramic materials analysis, which correspond to a total of 492 identifiable objects (NMI), mainly related to the $15^{\text {th }}$ and $16^{\text {th }}$ centuries.
\end{abstract}

Keywords: Urban Archaeology, Ceramics, Modern Age, $15^{\text {th }}-16^{\text {th }}$ Centuries, Vila Franca de Xira.

\section{INTRODUÇÃO}

O sítio do Ateneu Artístico Vilafranquense, situado no centro histórico de Vila Franca de Xira, era composto por diversas estruturas negativas preenchidas com materiais cuja análise permitiu definir diversas fases de ocupação do espaço situadas entre a formação da vila no século XIII e os nossos dias. Para além de três fossas de pequenas dimensões, destaca-se a presença de um silo, um poço e um tanque, bem como um troço de pavimento lajeado (Figura 1). Determinou-se que antes do final do século XV este local terá sido um espaço aberto utilizado como área de armazenamento, tratando-se provavelmente de uma zona de quintal anexo a um ou mais edifícios de habitação. Não podemos, porém, afastar a hipótese desta área ter então constituído uma zona periurbana dedicada ao armazenamento de víveres e à labo- ração agro-pastoril, sem qualquer espaço de habitação permanente. Entre final do século XV e inícios do século XVI observa-se o preenchimento de diversas estruturas, nomeadamente o silo e o tanque. Dado o importante volume de detritos domésticos descartados para o seu interior, parece evidente a existência no entorno de habitações de carácter permanente, pelo que esta área já estaria relativamente consolidada em termos urbanos. Nesta fase o poço encontrar-se-ia em funcionamento, embora não tenha sido possível averiguar a sua data de construção (Pires, 2019, pp. 110-115).

Posteriormente, entre a segunda metade do século XVI e a centúria seguinte, dá-se o preenchimento de uma das pequenas estruturas negativas. Baseado na datação de um azulejo encontrado no seu interior, o poço terá sido desactivado entre o final do século XVII e o terceiro quartel do século XVIII, antes da

1. Intituição: Faculdade de Ciências Sociais e Humanas. Universidade Nova de Lisboa; evaantunespires@gmail.com 
construção de um edificado visível numa planta de 1786 (Pimenta \& Mendes, 2016, pp. 190-191). Algures nesta data toda a zona terá sido aterrada para dar lugar a esta construção. Mais tarde, durante o século XIX, o edifício setecentista terá sido demolido para dar lugar ao antigo edifício do Ateneu Artístico Vilafranquense, que deu o nome a este local.

\section{A CERÂMICA}

Este sítio revelou uma grande diversidade de cerâmica destacando-se produções regionais, bem como importações. Neste conjunto, composto por 3361 fragmentos que correspondem a 492 peças identificáveis (NMI = Número Mínimo de Indivíduos), a observação das pastas permitiu identificar diversos grupos de fabrico repartidos por cerâmica fosca, brunida, vidrada e esmaltada. A cerâmica fosca é o grupo mais abundante, seguida pela cerâmica brunida, enquanto a presença da cerâmica vidrada e esmaltada é residual neste contexto (Gráfico 1).

A maioria das peças corresponde a produções do Vale do Tejo que terão origem local ou regional, colocando-se a hipótese de resultarem de uma produção vilafranquense (Gráfico 2). Outras peças, igualmente presentes em abundância, terão sido produzidas em Lisboa e, em menor número, no Barreiro e em Alenquer. As importações, embora se encontrem em quantidades residuais, têm origens diversas sendo oriundas principalmente de Sevilha, mas também de Montelupo, Brugges e possivelmente de Saintonge (Figura 2).

Em termos formais a cerâmica registada insere-se em diversas categorias relacionadas com o contexto doméstico, principalmente com o consumo, confecção e armazenamento de alimentos e líquidos. Observam-se ainda alguns objectos de higiene e iluminação, assim como materiais relacionados com actividades lúdicas e cerâmica de construção. A maioria das formas enquadra-se na cerâmica de cozinha que corresponde a $46 \%$ do NMI total, bem como na cerâmica de mesa, que representa $34 \%$.

\subsection{Cerâmica de produção local e/ou regional} A cerâmica que poderá ter sido produzida localmente constitui $45 \%$ da cerâmica registada no Ateneu Artístico Vilafranquense. Neste grupo inserem-se nomeadamente os fabricos $\mathrm{F}_{1} / \mathrm{B}_{1}$ e $\mathrm{F}_{2} / \mathrm{B}_{2}$ (Figuras 3 e 4), nos quais se enquadra a grande maioria das peças identificadas, bem como os fabricos F9 a F11, correspondentes a cerâmica de construção e afins que terá sido fabricada na vila. Assinala-se também a presença expressiva destas pastas noutros contextos vilafranquenses tais como o Museu do Neo-realismo (Pimenta \& Mendes, 2006; Mendes \& Pimenta, 2007). Estes fabricos apresentam pastas com abundantes inclusões de pequena a grande dimensão, sendo estas maioritariamente quartzo, assim como elementos de cor branca, preta e vermelha, com muito rara presença de micas. Em termos de coloração observam-se principalmente tons laranja e avermelhados resultantes de uma cozedura oxidante, por vezes de núcleo cinzento devido a uma cozedura redutora-oxidante. As superfícies, mais ou menos rugosas, são frequentemente recobertas por aguadas de tons semelhantes aos da pasta ou, mais raramente, com um engobe vermelho ou negro. Alguns exemplares apresentam superfícies brunidas, geralmente apenas na face interna.

A fraca presença de micas nestas pastas afasta a hipótese de uma origem nas olarias de Lisboa, embora os exemplares aqui registados apresentem numerosas semelhanças morfológicas com a cerâmica moderna exumada na capital, sendo por vezes idênticos (Pires, 2019, pp. 15-28). A confirmar-se como produções locais, estas copiariam de forma próxima os modelos da capital, como se atesta pelos paralelos com zonas de produção oleira localizadas na área da Mouraria, com cronologias situadas entre os séculos XV e XVII, nomeadamente na Rua do Benformoso (Marques, Leitão \& Botelho 2012, pp. 126-128), no Quarteirão dos Lagares (Nunes \& Filipe, 2012, pp. 143-145) e na Rua das Portas de Santo Antão (Cardoso \& alii, 2017, pp. 1718-1728). Embora menos frequentes, observam-se ainda alguns paralelos formais com peças produzidas entre finais do século XV e a primeira metade do século XVI no Barreiro, nomeadamente em Santo António da Charneca (Barros \& alii, 2012, pp. 702-703). O comércio de louça de barro entre Vila Franca de Xira e o exterior é comprovado pelo foral de 1510. Até à data, não se conhecem vestígios de nenhuma olaria desta época no interior da antiga vila, porém, o foral medieval concedido em 1212, refere a presença de fornos de louça, sugerindo a existência de produção oleira durante o século XIII (Camacho, 1985, pp. 147-175). Por outro lado, o foral quinhentista apenas refere a produção de telhas e tijolos, sendo incerto se nessa época ainda existia produção de louça de barro. Se essa produção tiver subsistido, a sua ausência neste foral pode indicar que não seria 
relevante na economia local face a outros produtos referidos no documento. A louça de barro seria possivelmente um complemento da produção de cerâmica de construção, à semelhança do que acontecia, por exemplo, na olaria do Alto do Castelo em Alcochete, em funcionamento durante os séculos $\mathrm{XV}$ -XVI (Correia, 2005/o7, pp. 67-73).

\subsection{Cerâmica de Lisboa}

As produções que terão origem nas olarias de Lisboa representam $44 \%$ da cerâmica identificada neste local. Neste conjunto enquadram-se os fabricos de pasta micácea, incluindo cerâmica fosca e brunida (fabricos $\mathrm{F}_{3} / \mathrm{B}_{3}$ a $\mathrm{F}_{5} / \mathrm{B}_{5}, \mathrm{~F}_{7}$ ), cerâmica vidrada (fabricos $\mathrm{V}_{1}$ e $\mathrm{V}_{2}$ ) e a faiança portuguesa (fabrico $\mathrm{E}_{4}$ ).

No caso da cerâmica fosca e brunida, as pastas apresentam abundantes inclusões de muito pequena dimensão onde se destaca uma grande quantidade de micas, quartzo e raros elementos ferruginosos e brancos. Na coloração das pastas observam-se maioritariamente tons bege rosado e avermelhados, com cozeduras em ambiente oxidante ou redutor-oxidante. As superfícies são lisas ou mediamente rugosas, possuindo geralmente aguadas de tons semelhantes às pastas e sendo por vezes brunidas. Conhecem-se diversas olarias na capital onde se encontram pastas semelhantes, nomeadamente na área da Mouraria (Castro \& alii, 2017, pp. 1737-1742; Marques Leitão \& Botelho, 2012, pp. 126-128, Nunes \& Filipe, 2012, pp. 143-146; Paula, 2019, pp. 98-117), em contextos situados cronologicamente entre os séculos XV e XVII, assim como na Rua das Portas de Santo Antão (Cardoso \& alii, 2017, pp. 1718-1728), contexto dos séculos XV-XVI.

Na cerâmica vidrada observam-se pastas de coloração vermelha ou alaranjada, num caso muito bem depurada com raras inclusões de cor branca (fabrico Vi), noutro caso com abundantes micas de pequena dimensão, raros quartzos e elementos de cor negra (fabrico V2). Em ambos observam-se superfícies recobertas de vidrado verde ou melado aplicado em ambas as faces da peça ou apenas no exterior. Embora as características das pastas apontem para uma produção lisboeta, assemelhando-se a desperdícios oleiros do século XVI e início do XVII do Largo das Olarias (Castro \& alii, 2017: 1737-1742) e da Praça da Figueira (Barradas \& Silva, 2017, pp. 1694-1700), não foi possível associar estes fabricos a nenhum contexto de produção específico.

A cerâmica esmaltada de origem lisboeta corres- ponde a faiança portuguesa, cuja produção se inicia na segunda metade do século XVI (Casimiro, 2013, pp. 355; Sebastian, 2012, pp. 937-943). Estas peças possuem uma pasta bege amarelada bem depurada e superfícies recobertas de esmalte branco com motivos pintados a azul-cobalto e, por vezes, a manganês. Conhecem-se vestígios de produção de faiança na capital, nomeadamente no Largo das Olarias entre a segunda metade do século XVI e início do XVII (Castro \& alii, 2017, pp. 1737-1742), na zona do Largo de Jesus, entre finais do século XVI e meados do XVII (Cardoso \& Batalha, 2015, pp.148-170), ou na Rua de Buenos Aires com uma cronologia situada nos séculos XVII-XVIII (Batalha $\&$ alii, 2012, pp. 952-962). É na Rua de Buenos Aires que se observam os exemplares mais semelhantes às formas vilafranquenses (Pires, 2019, pp. 59-6o). Porém, essas peças encontraram-se apenas no interior de uma das estruturas negativas de pequenas dimensões e no conjunto de materiais de superfície descontextualizados.

\subsection{Cerâmica do Barreiro e Alenquer}

No conjunto de cerâmica vidrada observam-se peças de pasta bege (fabrico $\mathrm{V}_{4}$ ), com muito raras inclusões de pequena dimensão, maioritariamente elementos ferruginosos e de cor negra, assim como alguns brancos. As suas superfícies encontram-se recobertas de vidrado melado ou verde. Este fabrico deverá corresponder a uma produção do Barreiro, com origem na Mata da Machada (Carmona \& Santos, 2005, pp. 14-16) ou em Santo António da Charneca (Barros \& alii, 2012, pp. 701-705), área oleira que funcionou entre finais do século XV e a primeira metade do século XVI. Embora seja complexo distinguir esta produção das importações sevilhanas, algumas características das pastas, nomeadamente as diferenças de textura, permitem considerar uma origem portuguesa para estes materiais (Coelho \& Teixeira, 2018, pp. 261-264).

Paralelamente, este fabrico poderá corresponder a uma produção de Alenquer, onde foi identificada uma olaria que se encontrou em funcionamento entre o final do século XV e início do XVII (Cardoso \& alii, 2016, pp. 56-62). Porém, embora as formas de Alenquer apresentem semelhanças com os exemplares aqui registados, a textura das pastas é distinta (Pires, 2019, pp. 50-52). De facto, as peças registadas no Ateneu Artístico Vilafranquense e associadas a Alenquer (fabrico $V_{5}$ ) possuem uma pasta bege rosada e menos rígida, com algumas inclusões de 
muito pequena dimensão, nomeadamente quartzo, micas e elementos de cor negra e branca. As superfícies encontram-se recobertas de vidrado amarelo esverdeado ou verde.

\subsection{Cerâmica de importação}

Apesar do claro predomínio das produções locais e regionais, existem igualmente elementos exógenos que, embora em quantidades residuais, apresentam origens diversas. Estas importações provêm nomeadamente de Espanha, Itália, Bélgica e França, representando no seu conjunto $6 \%$ do total da cerâmica do Ateneu Artísitco Vilafranquense. Destacam-se as produções sevilhanas que representam $5 \%$, correspondendo à quase totalidade das importações identificadas. As restantes produções têm origem em Montelupo, Brugges e Saintonge.

A localização de Vila Franca de Xira numa importante linha de comunicação fluvial, assim como a sua proximidade ao porto de Lisboa, facilitaria o acesso aos mercados regionais e europeus. De facto, Lisboa contava, desde os séculos XII-XIII, com a presença de importações do Sul peninsular e do Norte europeu, às quais se juntam as cerâmicas italianas nos séculos XV-XVI (Bettencourt \& alii, 2018, pp. 142). Porém, observa-se neste contexto a ausência de alguma cerâmica de importação que frequentemente se encontra em contextos arqueológicos portugueses de cronologia moderna, tais como objectos em grés oriundos do Norte da Europa ou porcelanas da China, assim como certas produções peninsulares tais como cerâmicas de corda-seca ou de reflexo metálico. Enquanto questões cronológicas poderiam explicar a inexistência das primeiras, sendo as porcelanas importadas maioritariamente a partir de finais do século XVI, não justificam a ausência de cerâmica de corda seca e reflexo metálico que se encontram nos contextos lisboetas entre a segunda metade do século XV e inícios do XVI (Silva \& Guinote, 1998, pp. 74-87). Além disso, os números relativos à presença de cerâmica importada são aqui reduzidos. Eventualmente a singularidade deste sítio pode residir no tipo de contexto arqueológico, um espaço possivelmente periurbano ou nas franjas do antigo aglomerado populacional, podendo ainda estar relacionada com o poder económico dos habitantes.

Nas importações sevilhanas encontramos maioritariamente cerâmica vidrada e esmaltada, assim como uma reduzida quantidade de cerâmica fosca, nomeadamente fragmentos de anforetas Spanish Olive Jars (fabrico F8), produzidas entre o final do século XV e durante século XVI (Amores Carredano \& Chisvert Jiménez, 1993, pp. 283-297; Pleguezuelo \& alii, 1999, p. 269). Estes recipientes eram objectos comuns utilizados no transporte marítimo ou fluvial de mercadorias, tendo-se recuperado diversos exemplares no rio Tejo na zona de Vila Franca de Xira (Calado, Pimenta \& Regala, 2000, pp. 106-107), assim como um exemplar no Museu do Neo-realismo (Pimenta \& Mendes, 2006, p. 23).

A cerâmica vidrada identificada como produção andaluza (fabrico $V_{3}$ ) possui uma pasta de cor bege ou bege rosada, com raras inclusões de muito pequena dimensão, nomeadamente quartzos e elementos brancos. Este fabrico, com origem nas olarias de Sevilha entre o século XV e durante o século XVI, distingue-se pela sua pasta de textura porosa e macia, bem como as suas superfícies recobertas de vidrado melado, amarelo ou verde que podem ser decoradas com riscos a manganês (Pleguezuelo \& Lafuente, 1995, pp. 226-236).

No conjunto de cerâmica esmaltada de origem sevilhana registam-se dois grupos de fabrico, ambos de pasta bege com superfícies recobertas de esmalte branco (fabricos E1 e E2). O primeiro enquadra-se na série blanca lisa ou Columbia Plain produzida em Sevilha durante os séculos XV-XVI (Pleguezuelo \& Lafuente, 1995, pp. 226-236). Alguns investigadores afirmam que este tipo de cerâmica terá sido produzido em Portugal durante o século XVI na olaria da Mata da Machada (Casimiro, 2013, pp. 354). Porém, a ausência nesse local de peças esmaltadas a branco com defeitos de fabrico, mas antes com marcas de uso, indica que estas correspondem provavelmente a objectos de consumo importados do Sul peninsular e não restos de produção local (Coelho \& Teixeira, 2018, pp. 264). Em Coimbra identificaram-se cerâmicas esmaltadas a branco que poderão ter sido produzidas localmente a partir de meados do século XVI, embora essas pastas possuam maior abundância de inclusões, distinguindo-se dos exemplares do Ateneu Artístico Vilafranquense que atribuímos a Sevilha (Sebastian, 2012, pp. 941-945). Estas peças andaluzas encontram-se frequentemente em contextos portugueses dos séculos XV-XVI, nomeadamente em Vila Franca De Xira (Mendes \& Pimenta, 2007, pp. 69-75) e em Lisboa (Sabrosa, 2008, pp. 111-117; Martingil, 2015, pp. 431-433). Estas estão ainda presentes em contextos lisboetas dos séculos XVI-XVII como, por exemplo, no Hospital 
Real de Todos-os-Santos (Silva $\mathbb{Z}$ alii, 2012, pp. 71-8o). Neste conjunto identificou-se ainda uma tigela com um escorrimento de vidrado verde aplicado sobre o esmalte branco, enquadrando-se na série blanco $y$ verde de mitades ou Columbia Plain white and green, produzida entre o século XV e início do XVI (Pleguezuelo \& Lafuente, 1995, pp. 228). Exemplares semelhantes encontram-se igualmente em contextos dos séculos XV-XVI, nomeadamente em Lisboa (Gonzalez, 2012a, pp. 87-88) ou em Palmela (Fernandes \& Carvalho, 1998, pp. 222-246).

O segundo fabrico de cerâmica esmaltada andaluza distingue-se por uma pasta mais porosa e pela presença de decoração geométrica a azul-cobalto e manganês sobre a superfície interna. Este grupo de fabrico enquadra-se na série azul y morada ou Isabella Polychrome produzida entre o final do século XV e início do XVI nas olarias sevilhanas (Pleguezuelo \& Lafuente, 1995, pp. 228-236). Também estas peças são frequentes em contextos situados entre os séculos XV-XVI (Mendes \& Pimenta, 2007, pp. 76 -77; Teixeira, Villada Paredes \& Silva, 2015, pp. 202; Sabrosa, 2008, pp. 113).

A cerâmica com origem nas olarias italianas de Montelupo corresponde a pratos esmaltados a branco e decorados com motivos geométricos pintados a azul-cobalto, laranja e vermelho. As peças registadas neste sítio apresentam pastas brancas e porosas e encontram-se decoradas com o motivo ad ovali e rombi. Esta majólica, produzida durante os séculos XV e XVI, é comum nos contextos arqueológicos lisboetas dessa época (Felício \& alii, 2017, pp. 1812-1819; Gonzalez, 2012b, pp. 850-853; Martingil, 2015, pp. 431-433; Sabrosa, 2008, pp. 138), encontrando-se igualmente em níveis do século XVI e início do XVII (Barradas, Silva, 2017, pp. 1697-1702; Silva \& alii, 2012, pp. 71-77). Infelizmente, no Ateneu Artístico Vilafranquense, estas peças encontraram-se apenas no conjunto de materiais de superfície descontextualizados.

A cerâmica importada de Brugges caracteriza-se por uma pasta de cor vermelha alaranjada, com inclusões de quartzo de pequena dimensão. A superfície externa é recoberta de vidrado verde que se sobrepõe a um engobe branco visível entre o vidrado e a pasta. Esta cerâmica flamenga, produzida entre o final do século XIII e a primeira metade do XIV, encontra-se em alguns contextos lisboetas dessa época (Oliveira \& alii, 2017, pp. 1528-1536; Teixeira, Villada Paredes \& Silva, 2015, pp. 179).
O grupo de fabrico que poderá corresponder às produções de Saintonge apresenta uma pasta de cor cinza ou esbranquiçada, com muitas inclusões de pequena e média dimensão, nomeadamente quartzos, micas e raros elementos ferruginosos. As superfícies possuem vidrado verde aplicado em ambas as superfícies ou apenas na face externa. Observa-se maioritariamente o grupo de vidrado liso denominado Saintonge Bright Green, existindo também um fragmento de vidrado manchado correspondente ao grupo Saintonge Motled Green (Haggarty, 2006, pp. 22-57). Todavia, não descartamos a possibilidade de alguns fragmentos enquadrados neste fabrico corresponderem a uma produção do Norte de França e não de Saintonge, dada a dificuldade em distinguir os fabricos dessas regiões a partir de fragmentos de pequena dimensão. Estas produções francesas eram importadas durante os séculos XIII-XIV, encontrando-se em contextos lisboetas dessa época (Oliveira \& alii, 2017, pp. 1527-1534) ou do início do século XV (Pinheiro, 2015, pp. 41).

\section{CASO DE ESTUDO: O SILO}

No que toca às estruturas reveladas nesta intervenção, o caso do silo é o mais claro. Trata-se de uma estrutura muito comum nos aglomerados urbanos portugueses medievais. Inicialmente utilizado para o armazenamento de alimentos, particularmente cereais, os silos eram entulhados quando a sua função de armazenamento se tornava obsoleta, podendo ser substituídos por talhas ou pela utilização de celeiros (Silva, 2003, pp. 57). A datação dos materiais cerâmicos e, mais precisamente, a identificação de um ceitil de D. João II, sendo este o objecto de cronologia segura mais recente registado no seu interior, coloca o preenchimento do silo no final do século XV. Todavia, tendo em consideração o período de circulação dos numismas, podemos eventualmente avançar a cronologia de formação deste depósito para os inícios do século XVI (Teixeira, Villada Paredes, Silva, 2015, pp. 217).

Este silo é o contexto conservado com mais abundância de espólio, contendo $45 \%$ da cerâmica recuperada neste local. Este conjunto, constituído por cerâmica fosca (65\%), brunida (24\%), vidrada ( $8 \%$ ) e esmalta (2\%), é composto maioritariamente por produções do Vale do Tejo que possuem uma vasta continuidade, não permitindo o estabelecimento de cronologias seguras. Dentro destas regista-se 
cerâmica possivelmente de origem local (fabricos F1/B1, F2/B2 e F9), bem como produções de Lisboa (fabricos $\mathrm{F}_{3} / \mathrm{B}_{3}$ a F5/B5, F7, V1 e V2) e do Barreiro (fabrico $\mathrm{V}_{4}$ ). Em termos formais, na cerâmica fosca observa-se a abundância de peças de cozinha, principalmente panelas, bem como um número significativo de cerâmica de mesa e de armazenamento, compostas maioritariamente por púcaros e potes, respectivamente. Na cerâmica brunida as formas mais abundantes correspondem à cerâmica de mesa representada por pratos, púcaros e tigelas, encontrando-se em menores quantidades as peças de cozinha e de higiene.

Neste conjunto identificaram-se igualmente fragmentos de cerâmica importada, alguns correspondendo a uma produção sevilhana enquanto outros serão oriundos do Norte da Europa. No conjunto de cerâmica sevilhana destaca-se a presença de fragmentos de anforetas Spanish Olive Jar (fabrico F8), bem como peças vidradas (fabrico $\mathrm{V}_{3}$ ) e esmaltadas (fabricos $E_{1}$ e E2). As peças vidradas correspondem a um prato vidrado a melado com riscos a manganês e um alguidar vidrado a verde, enquanto na cerâmica esmaltada observam-se pratos e tigelas. Estas peças esmaltadas correspondem maioritariamente à série blanca lisa, encontrando-se ainda um fragmento de prato enquadrado na série azul y morada. Na cerâmica proveniente do Norte europeu destaca-se a produção flamenga de Brugges (fabrico V9) e as produções francesas de Saintonge (fabrico V6). Ambas contabilizam apenas alguns fragmentos vidrados a verde, não tendo sido possível reconstituir nenhuma forma.

Em suma, neste silo encontra-se cerâmica de cozinha, mesa e armazenamento, bem como objectos relacionados com a higiene, iluminação e a prática de uma actividade lúdica (Gráfico 3). A cerâmica de mesa é a categoria mais abundante e diversificada, observando-se ainda percentagens significativas de cerâmica de cozinha e de armazenamento. Embora individualmente as panelas sejam a forma mais representada, a estas seguem-se os púcaros, tigelas e pratos. A abundância de cerâmica de mesa dever-se-á à transformação dos hábitos alimentares durante o final da Idade Média, época na qual o consumo se individualiza, multiplicando-se os recipientes tais como pratos e tigelas. $\mathrm{O}$ aumento de pratos aponta também para a presença de refeições mais sólidas, que ao invés dos ensopados não necessitavam de ser consumidas em recipientes fundos (Silva, 2003, pp.
56-75). Porém, o predomínio das panelas em relação aos tachos e frigideiras, sugere que os alimentos seriam consumidos maioritariamente sob a forma de cozidos ou ensopados (Casimiro, Boavida \& Detry, 2017, pp. 112-114).

A distribuição das formas pelos diferentes tipos de cerâmica poderá assinalar preferências da população. Neste conjunto denota-se a preferência pela cerâmica fosca no que toca ao armazenamento de alimentos e líquidos. Também na confecção de alimentos utilizava-se maioritariamente cerâmica fosca, particularmente no caso das panelas, as quais são fabricadas exclusivamente nesse tipo. Porém, nos tachos e frigideiras observam-se igualmente peças brunidas, o que poderá estar relacionado com o tipo de cozinhados para os quais seriam utilizados, podendo estes beneficiar de superfícies alisadas e menos aderentes (Casimiro, Boavida \& Detry, 2017, pp. 112-114). Na cerâmica de mesa a diversidade de tipos sugere uma maior exigência com a qualidade dos recipientes utilizados no consumo de alimentos face às peças utilizadas na sua confecção e armazenamento. Enquanto no consumo de líquidos registamos uma preferência pela cerâmica fosca e brunida, nos pratos e tigelas destaca-se a maior abundância de cerâmica brunida e vidrada, bem como algumas peças esmaltadas. Dessa forma, podemos depreender que estas seriam preteridas pelas suas superfícies lisas e impermeabilizadas, não se excluindo possíveis questões estéticas e de estatuto social, particularmente no caso das peças importadas.

\section{CONCLUSÕES}

A análise do espólio do Ateneu Artístico Vilafranquense revelou uma grande diversidade de cerâmica, com a presença de várias produções regionais, assim como escassas peças importadas. Observou-se que a cerâmica regional compõe a maioria deste conjunto, sendo constituída por produções do Vale do Tejo provenientes nomeadamente de Lisboa, do Barreiro e de Alenquer, colocando-se a hipótese também de uma produção local, que carece de confirmação arqueológica. Mesmo a cerâmica de pasta não micácea, que não terá sido produzida em Lisboa, apresenta formas semelhantes ou idênticas às que aí encontramos, evidenciando uma certa padronização desta cerâmica a nível regional. Dessa forma, podemos concluir que a proximidade de Lisboa teria um impacto significativo no consumo das 
populações das vilas próximas que tinham acesso ao seu mercado. Esta poderá ter sido tanto uma questão de gosto, devido à eventual popularidade e qualidade destes produtos face a outros, assim como de acesso aos mesmos.

Em relação às importações, registou-se a presença maioritária de produções sevilhanas, bem como algumas peças com origem em Montelupo, Saintonge e Brugges, cerâmicas que se encontram frequentemente nos contextos portugueses de época tardomedieval e moderna. Ressalta, porém, a sua escassez, bem como a ausência de alguns materiais geralmente presentes em contextos desta época.

Em termos formais, constatou-se que a cerâmica identificada se relaciona principalmente com o consumo, confecção e armazenamento de alimentos, observando-se ainda alguns objectos relacionados com a higiene e iluminação. Em quantidades residuais encontram-se peças relacionadas com uma actividade lúdica, assim como cerâmica de construção. Estes dados permitem inferir o cariz doméstico deste contexto, composto por restos de consumo da população urbana. Embora a cerâmica de cozinha seja a categoria predominante neste conjunto, denota-se a abundância da cerâmica de mesa, sugerindo uma prática de consumo mais individualizada.

\section{BIBLIOGRAFIA}

AMORES CARREDANO, Fernando; CHISVERT JIMÉNEZ, Nieves (1993) - Tipología de la Cerámica Común Bajomedieval y Moderna Sevillana (s. XV-XVIII): I, la Loza Quebrada de Relleno de Bóvedas. SPAL: Revista de prehistoria y arqueología de la Universidad de Sevilla. Sevilla. 2, pp. 269-235.

BARRADAS, Ana Isabel; SILVA, Rodrigo Banha da (2017)Cerâmicas quinhentistas vidradas de um poço medieval da Praça da Figueira (Lisboa). In ARNAUD, José Morais; MARTINS, Andreia, coords. - Arqueologia em Portugal - 2017. Estado da questão. Actas do IIo Congresso da Associação dos Arqueólogos Portugueses Lisboa: Associação dos Arqueólogos Portugueses, pp. 1691-1702.

BARROS, Luís; BATALHA, Luísa; CARDOSO, Guilherme; GONZALES, António (2012) - A Olaria Renascentista de Santo António da Charneca - Barreiro. A Louça Doméstica. In TEIXEIRA, André; BETTENCOURT, José António, coords. - Velhos e Novos Mundos: Estudos de Arqueologia Moderna (ArqueoArte 1). 2. Lisboa: Centro de História de Além-Mar, pp. 699-710.

BATALHA, Luísa; CAMPÕA, Andreia; CARDOSO, Guilherme; NETO, Nuno; REBELO, Paulo, SANTOS, Raquel (2012) - Vestígios de um Centro Produtor de Faiança dos
Séculos XVII e XVIII. Dados de uma Intervenção Arqueológica Na Rua de Buenos Aires, n.ํำ 10, Lisboa. In TEIXEIRA, André; BETTENCOURT, José António, coords. - Velhos e Novos Mundos: Estudos de Arqueologia Moderna (ArqueoArte 1). 2. Lisboa: Centro de História de Além Mar, pp. 951-962.

BETTENCOURT, José; COELHO, Inês Pinto; FONSECA, Cristóvão; LOPES, Gonçalo; CARVALHO, Patrícia; SILVA, Tiago (2018) - Entrar e sair de Lisboa na época moderna: uma perspectiva a partir da arqueologia marítima. In SENNAMARTINEZ, João Carlos; MARTINS, Ana Cristina; CAESSA, Ana; MARQUES, António; CAMEIRA, Isabel, coords. - Meios, vias e trajetos... entrar e sair de Lisboa: Fragmentos de Arqueologia de Lisboa 2. Lisboa: Câmara Municipal de Lisboa/ Sociedade de Geografia de Lisboa, pp. 146-161.

CALADO, Marco; PIMENTA, João; REGALA, Frederico (200o) - Olive Jars Encontradas no Tejo. In Al-Madan. Almada. Série II. 9, pp. 206-207.

CAMACHO, Clara Frayão, coord. (1985) - Fontes Documentais - Forais do concelho de Vila Franca de Xira. In Boletim Cultural. Vila Franca de Xira. 1, pp. 147-175.

CARDOSO, Guilherme; GOMES, João José Fernandes; RODRIGUES, Severino; BATALHA, Luísa (2016) - Produção Oleira Renascentista na Bacia Hidrográfica do Baixo Tejo: a produção de cerâmicas vidradas em Alenquer, durante o século XVI. In Al-madan Online. Almada. Série II, 20: 2, pp. 54-63.

CARDOSO, Guilherme; BATALHA, Luísa; REBRLO, Paulo; ROCHA, Miguel; NETO, Nuno; BRITO, Sara (2017) - Uma olaria na Rua das Portas de Santo Antão (Lisboa) séculos XV e XVI. In ARNAUD, José Morais; MARTINS, Andreia, coords. - Arqueologia em Portugal - 2017. Estado da questão. Actas do II ${ }^{\circ}$ Congresso da Associação dos Arqueólogos Portugueses. Lisboa: Associação dos Arqueólogos Portugueses, pp. 1715-1719.

CARDOSO, Guilherme; BATALHA, Luísa (2015) -Evidências de produção oleira dos finais do século XVI a meados do século XVII no Largo de Jesus (Lisboa). In SENNA MARTINEZ, João Carlos; MARTINS, Ana Cristina; MELO, Ana Ávila de; MARQUES, António; CAMEIRA, Isabel, CAESSA, Ana, eds. - I Encontro de Arqueologia de Lisboa: Uma Cidade em Escavação. Lisboa: Câmara Municipal de Lisboa/ Sociedade de geografia de Lisboa, pp. 147-181.

CARMONA, Rosalina; SANTOS, Cátia (2005) - Olaria da Mata da Machada. Cerâmicas dos séculos XV-XVI. Barreiro: Camara Municipal do Barreiro.

CASIMIRO, Tânia Manuel (2013) - Faiança portuguesa: datação e evolução crono-estilística. Revista Portuguesa de Arqueologia. Lisboa. 16, pp. 351-367.

CASIMIRO, Tânia Manuel; BOAVIDA, Carlos; DETRY, Cleia (2017) - Cozinhar e comer: cerâmicas e alimentação em Carnide (1550-1650). In SENNA MARTINEZ, João Carlos; MARTINS, Ana Cristina; MELO, Ana Ávila de; MARQUES, António; CAMEIRA, Isabel, CAESSA, Ana, eds. - I 
Encontro de Arqueologia de Lisboa: Uma Cidade em Escavação. Lisboa: Câmara Municipal de Lisboa / Sociedade de geografia de Lisboa, pp. 110-121.

CASTRO, Anabela; PAULA, Nuno Amaral de; TORRES, Joana, CURADO, Tiago; TEIXEIRA, André (2017) - Evidências de produção oleira nos séculos XVI e XVII no Largo das Olarias, Mouraria (Lisboa). In ARNAUD, José Morais; MARTINS, Andreia, coords. - Arqueologia em Portugal 2017. Estado da questão. Actas do II ${ }^{\circ}$ Congresso da Associação dos Arqueólogos Portugueses. Lisboa: Associação dos Arqueólogos Portugueses, pp. 1731-1749.

COELHO, Inês Pinto; TEIXEIRA, André (2018) - Glazed pottery production from Mata da Machada, Barreiro (Portugal). In KARAKAYA, Defne; LITTLE, Timothy Glenn, eds. - Medieval and Modern Period Mediterranean Ceramics. Ankara: Koç Universitesi VEKAM, pp. 261-265.

CORREIA, Miguel (2005/2007) - Um forno de produção cerâmica dos séculos XV-XVI, em Alcochete. In Musa. Setúbal. 2, pp. 67-73.

FELÍCIO, Catarina; SOUSA, Filipe; GUIMARÃES, Raquel; GADANHO, André (2017) - A cerâmica italiana dos séculos XV e XVI do Largo do Jogo da Bola em Carnide, Lisboa. In ARNAUD, José Morais; MARTINS, Andreia, coords. Arqueologia em Portugal - 2017. Estado da questão. Actas do II ${ }^{o}$ Congresso da Associação dos Arqueólogos Portugueses. Lisboa: Associação dos Arqueólogos Portugueses, pp. 1809-1820.

FERNANDES, Isabel Cristina.; CARVALHO, A. Rafael (1998) - Conjuntos Cerâmicos Pós-Medievais de Palmela. In DIOGO, João Manuel; ABRAÇOS, Hélder Chilra, eds. Actas das 2 $2^{\underline{a}}$ Jornadas de Cerâmica Medieval e Pós-Medieval. Métodos e resultados para o seu estudo. Tondela: Câmara Municipal de Tondela, pp. 211-255.

GONZALEZ, Cristina (2012a) - Os novos espaços da cidade moderna. Uma aproximação à Ribeira de Lisboa através de uma intervenção no Largo do Terreiro do Trigo. In TEIXEIRA, André; BETTENCOURT, José António, coords. Velhos e Novos Mundos: Estudos de Arqueologia Moderna. (ArqueoArte 1). 1. Lisboa: Centro de História de Além Mar, pp. 85-94.

GONZALEZ, Cristina (2012b) - Majólicas italianas do Terreiro do Trigo (Lisboa). In TEIXEIRA, André; BETTENCOURT, José António, coords. - Velhos e Novos Mundos: Estudos de Arqueologia Moderna. (ArqueoArte 1). 2. Lisboa: Centro de História de Além Mar, pp. 847-854.

HAGGARTY, George (2006) - A gazetteer and summary of French pottery imported into Scotland c. 1150 to c. 1650 a ceramic contribution to Scotland's economic history Ceramic Resource. In Tayside and Fife Archaeological Journal. 12: 3, pp. 117-118.

LUCAS, Maria Miguel (2003) - Vila Franca de Xira: História, Urbanismo e Identidade. In Vila Franca de Xira: Tempos do Rio, Ecos da Terra. Vila Franca de Xira: Câmara Municipal de Vila Franca de Xira, pp. 99-106.

MARQUES, António; LEITÃO, Eva; BOTELHO, Paulo (2012) - Rua do Benformoso 168/186 (Lisboa-Mouraria/Intendente). Entre a nova e a velha cidade, aspectos da sua evolução urbanística. In TEIXEIRA, André; BETTENCOURT, José António, coords. - Velhos e Novos Mundos: Estudos de Arqueologia Moderna. (ArqueoArte 1). 1. Lisboa: Centro de História de Além Mar, pp. 123-134.

MARTINGIL, Márcio (2015) - Testemunhos Arqueológicos na Rua do Jardim do Regedor nํำ a 32, Lisboa. In CAESSA, Ana; NOZES, Cristina; CAMEIRA, Isabel, SILVA, Rodrigo Banha da, eds. - I Encontro de Arqueologia de Lisboa: Uma Cidade em Escavação. Lisboa: Câmara Municipal de Lisboa, pp. 426-439.

MENDES, Henrique; PIMENTA, João (2007) - Contexto quinhentista das escavações do Museu do Neo-Realismo. Vila Franca de Xira: Câmara Municipal de Vila Franca de Xira.

NUNES, Tiago; FILIPE, Iola (2012) - Quarteirão dos Lagares. Contributo para a História económica da Mouraria. In TEIXEIRA, André; BETTENCOURT, José António, coords. - Velhos e Novos Mundos: Estudos de Arqueologia Moderna. (ArqueoArte 1). 1. Lisboa: Centro de História de Além-Mar, pp. 141-150.

OLIVEIRA, Filipe; SILVA, Rodrigo Banha da; BARGÃO, André; FERREIRA, Sara (2017) - O comércio medieval de cerâmicas importadas em Lisboa: O caso da Rua das Pedras Negras n.ํㅗ 22-28. In ARNAUD, José Morais; MARTINS, Andreia, coords. - Arqueologia em Portugal-2017. Estado da questão. Actas do II ${ }^{\circ}$ Congresso da Associação dos Arqueólogos Portugueses. Lisboa: AAP - Associação dos Arqueólogos Portugueses, pp. 1523-1538.

PAULA, Nuno (2019) - A produção oleira na Lisboa dos séculos XVI e XVII: Um forno cerâmico no Largo das Olarias (Mouraria). Dissertação de Mestrado em Arqueologia / Faculdade de Ciências Sociais e Humanas / Universidade Nova de Lisboa.

PIMENTA, João; MENDES, Henrique (2006) - Relatório escavações do Museu do Neo-realismo (Vila Franca de Xira). Vila Franca de Xira: Município de Vila Franca de Xira/Divisão de Património e Museus.

PIMENTA, João; MENDES, Henrique (2016) - Carta Arqueológica de Vila Franca de Xira. Vila Franca de Xira: Câmara Municipal de Vila Franca de Xira.

PINHEIRO, Helena (2015) - Arqueologia Urbana em Lisboa: o Convento do Carmo entre os séculos XIV e XIX. Relatório de Estágio de Mestrado em Arqueologia/Faculdade de Ciências Sociais e Humanas/Universidade Nova de Lisboa.

PINTO, Maria Adelaide (2007) - Relatório Final da Intervenção Arqueológica no Ateneu Artístico Vilafranquense, Torres Novas: Crivarque, Lda. 
PIRES, Eva (2019) - O sítio Ateneu Artístico Vilafranquense (Vila Franca de Xira): contributo para o conhecimento do quotidiano nos séculos XVe XVI. Dissertação de Mestrado em Arqueologia / Faculdade de Ciências Sociais e Humanas / Universidade Nova de Lisboa.

PLEGUEZUELO, Alfonso; LAFUENTE, M. Pilar (1995) Cerámicas de Andalucia Ocidental (1200-16oo). In GERRARD, Christopher M.; GUTIERREZ, Alejandra; VINCE, Alan G., eds. - Spanish medieval ceramics in Spain and the British Isles. Cerámica medieval española en España y en las Islas Británicas. (BAR International Series.610), pp. 217-244.

PLEGUEZUELO, Alfonso; LIBRERO, Antonio; ESPINOSA, María; MORA, Pedro (1999) - Loza Quebrada” Procedente de la Capilla del Colegio-Universidad de Santa María de Jesús (Sevilla). In SPAL: Revista de prehistoria y arqueología de la Universidad de Sevilla. 8, pp. 263-294.

FERNANDES, Isabel Cristina F.; CARVALHO, A. Rafael (1998) - Conjuntos Cerâmicos Pós-Medievais de Palmela. In DIOGO, João Manuel; ABRAÇOS, Hélder Chilra, eds. Actas das $2^{\underline{a}}$ Jornadas de Cerâmica Medieval e Pós-Medieval. Métodos e resultados para o seu estudo. Tondela: Câmara Municipal de Tondela, pp. 211-255.

SABROSA, Armando (2008) - As faianças da Casa Côrte-Real, Largo do Corpo Santo, Lisboa. In DIOGO, João Manuel, coord. - Actas das $4^{\underline{a}}$ Jornadas de Cerâmica Medieval e Pós-Medieval. Métodos e resultados para o seu estudo. Tondela: Câmara Municipal de Tondela, pp. 109-142.

SEBASTIAN, Luís (2012) - Faiança Portuguesa. Centros produtores, matérias, técnicas de fabrico e critérios de distinção", In TEIXEIRA, André; BETTENCOURT, José António, coords. - Velhos e Novos Mundos: Estudos de Arqueologia Moderna. (ArqueoArte 1). 2. Lisboa: Centro de História de Além Mar, pp. 937-950.

SILVA, Rodrigo Banha da (2003) - Olaria medieval e dos Descobrimentos do Vale do Tejo: um Enquadramento. In Olaria portuguesa: do fazer ao usar. Lisboa: Assírio \& Alvim, pp. 35-61.

SILVA, Rodrigo Banha da; GUINOTE, Paulo (1998) - O Quotidiano na Lisboa dos Descobrimentos. Roteiro dos lugares e objectos. Lisboa: Ministério da Educação.

SILVA, Rodrigo Banha da; MIRANDA, Pedro; VIEIRA, Vasco Noronha; VICENTE, António Moreira; LOPES, Gonçalo C.; NOZES, Cristina (2012) - Largo do Chafariz de Dentro: Alfama em Época Moderna, In TEIXEIRA, André; BETTENCOURT, José António, coords. - Velhos e Novos Mundos: Estudos de Arqueologia Moderna. (ArqueoArte 1). 2. Lisboa, Centro de História de Além-Mar, pp.71-84.

TEIXEIRA, André; VILLADA PAREDES, Fernando; SILVA, Rodrigo Banha da, coords. (2015) - Lisboa 1415 Ceuta: historia de dos ciudades - história de duas cidades. Ciudad Autonoma de Ceuta / Câmara Municipal de Lisboa. 


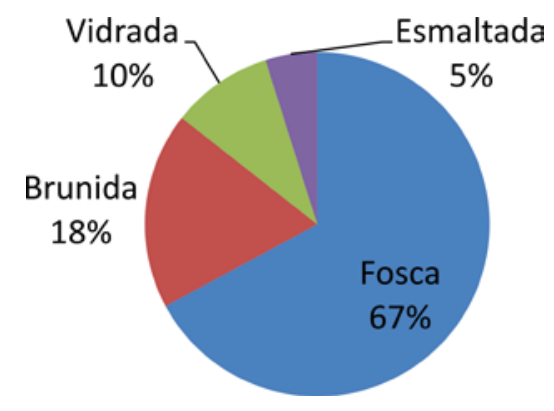

Gráfico 1 - Distribuição do conjunto de cerâmica do Ateneu Artístico Vilafranquense por tipo.

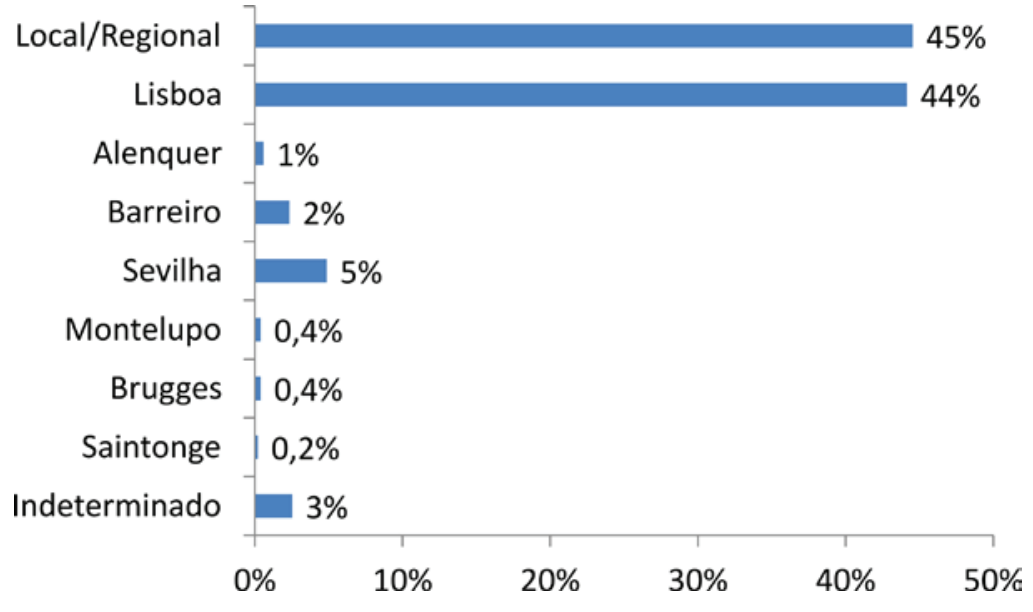

Gráfico 2-Distribuição dos fabricos identificados no conjunto de cerâmica do Ateneu Artístico Vilafranquense.

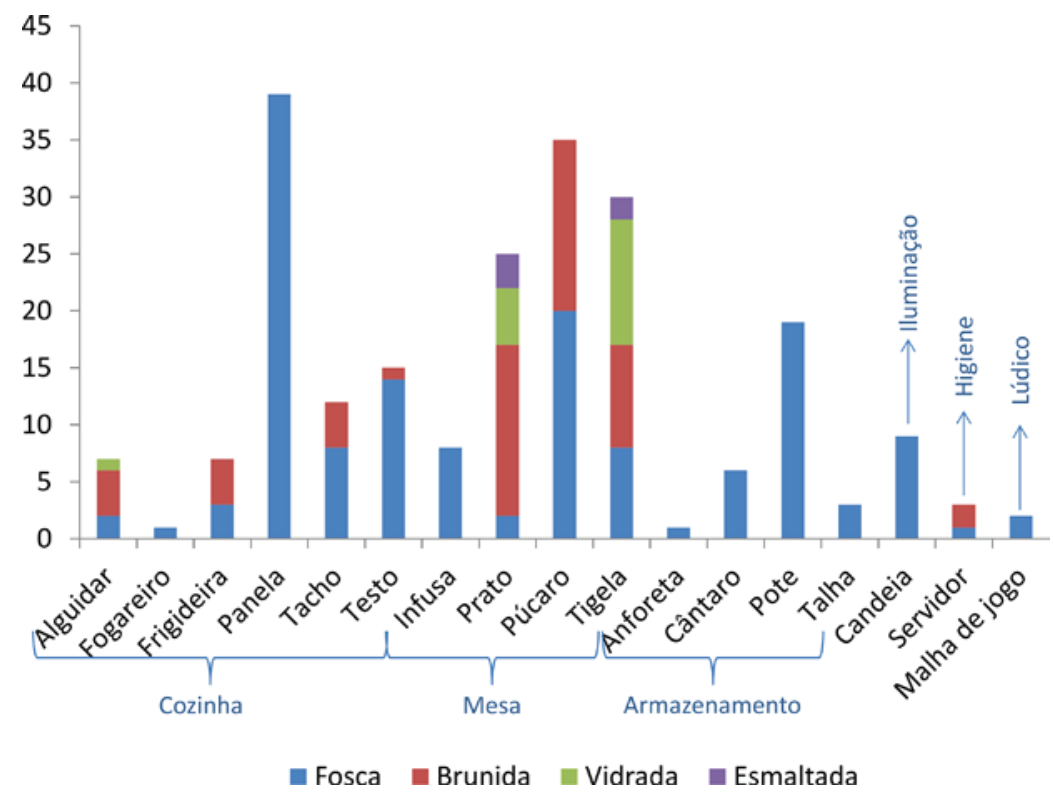

Gráfico 3 - Distribuição do NMI das peças identificadas no silo, por forma e tipo de cerâmica. 


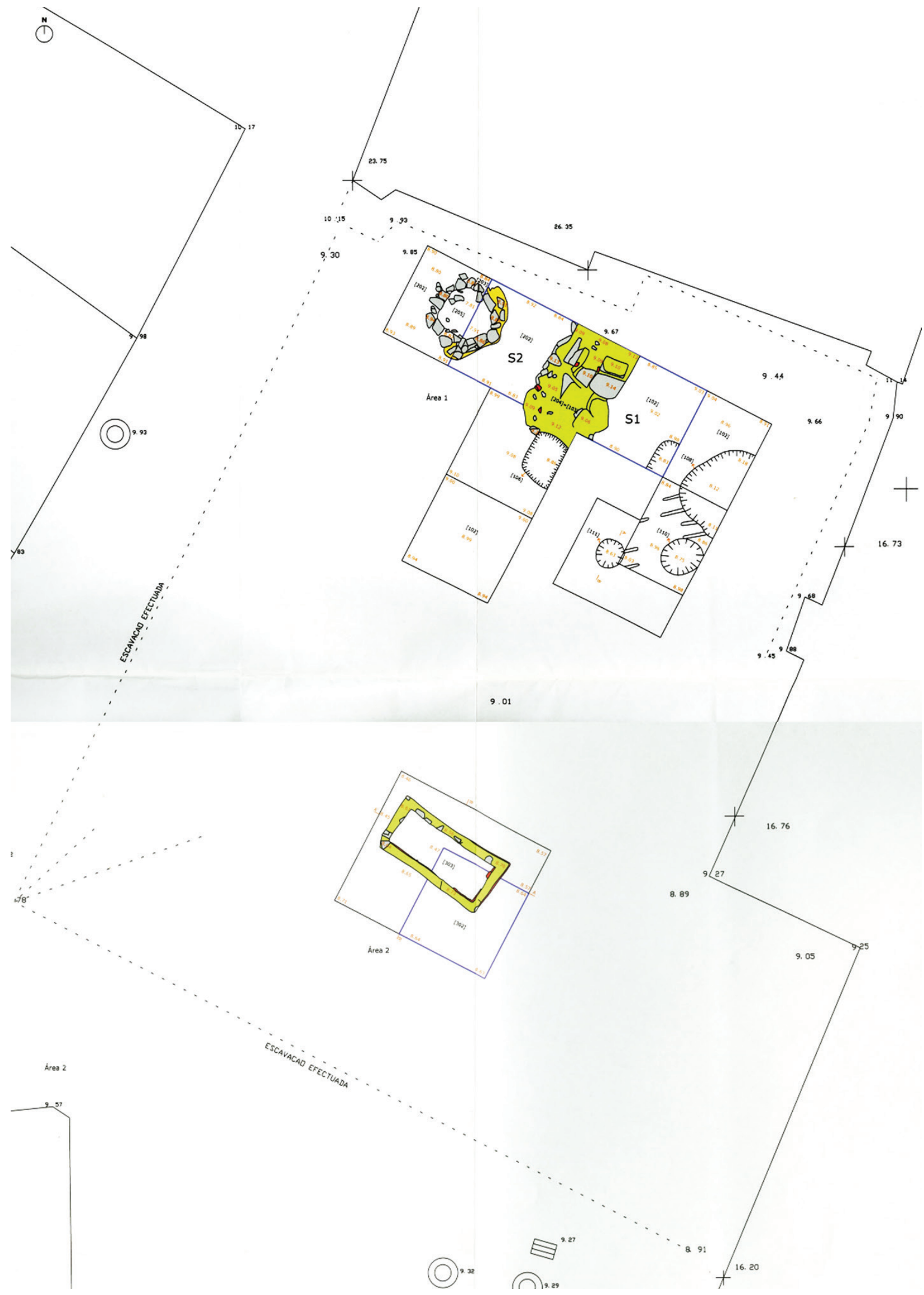

Figura 1 - Plano final da intervenção arqueológica no sítio do Ateneu Artístico Vilafranquense (In Pinto, 2007, Anexo III). 203 = poço; $204 / 203=$ pavimento lajeado; 106,110 e $111=$ estruturas negativas de pequenas dimensões; $108=$ silo; $304=$ tanque . 
Local/regional

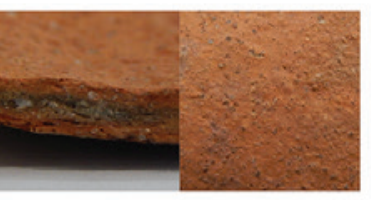

F1/B1

Lisboa

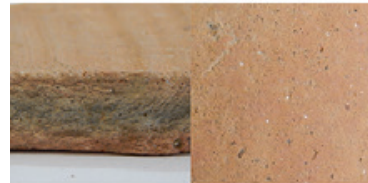

F3/B3

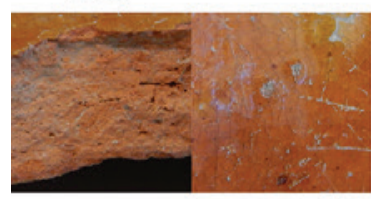

v1

Barreiro

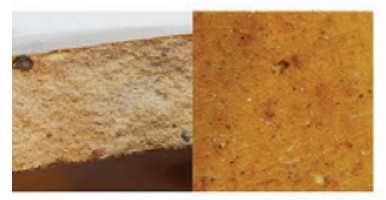

v4

Sevilha

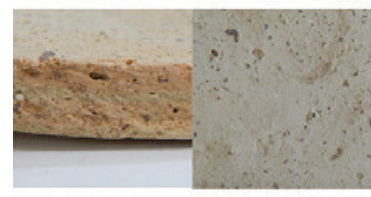

F8

Saintonge

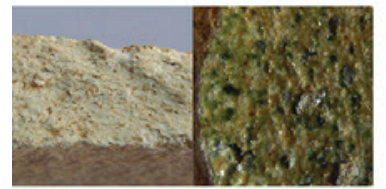

v6

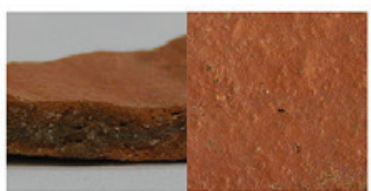

F2/B2

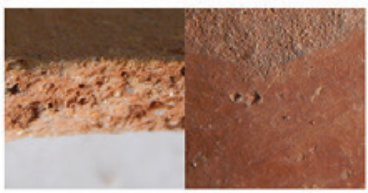

F4/B4

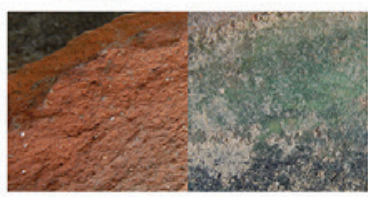

v2

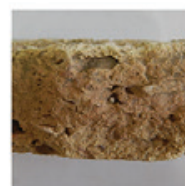

F9

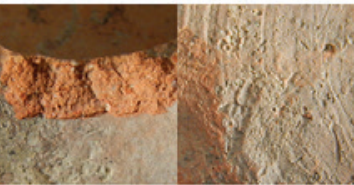

F5/B5

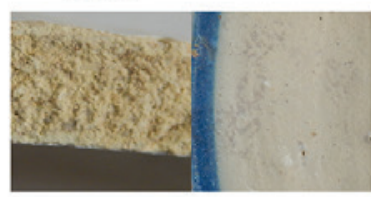

E4

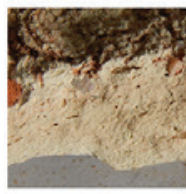

F10

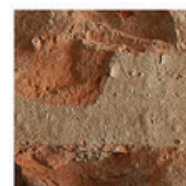

F11

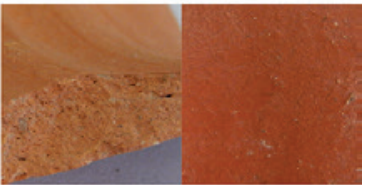

F7

\section{Alenquer}

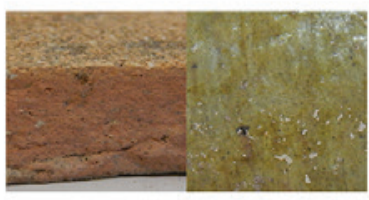

v5

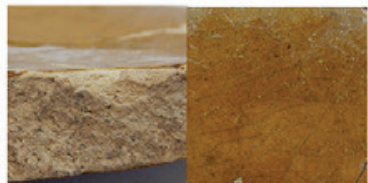

v3

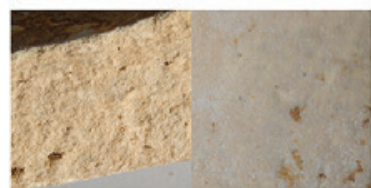

E1

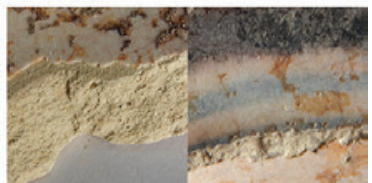

E2
Brugges

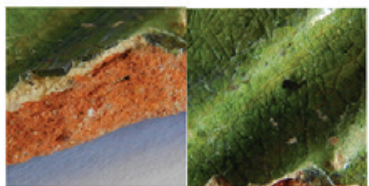

v9
Montelupo

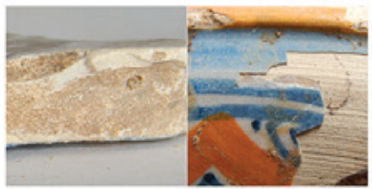

E3

Figura 2 - Pormenores dos fabricos identificados no Ateneu Artístico Vilafranquense. 

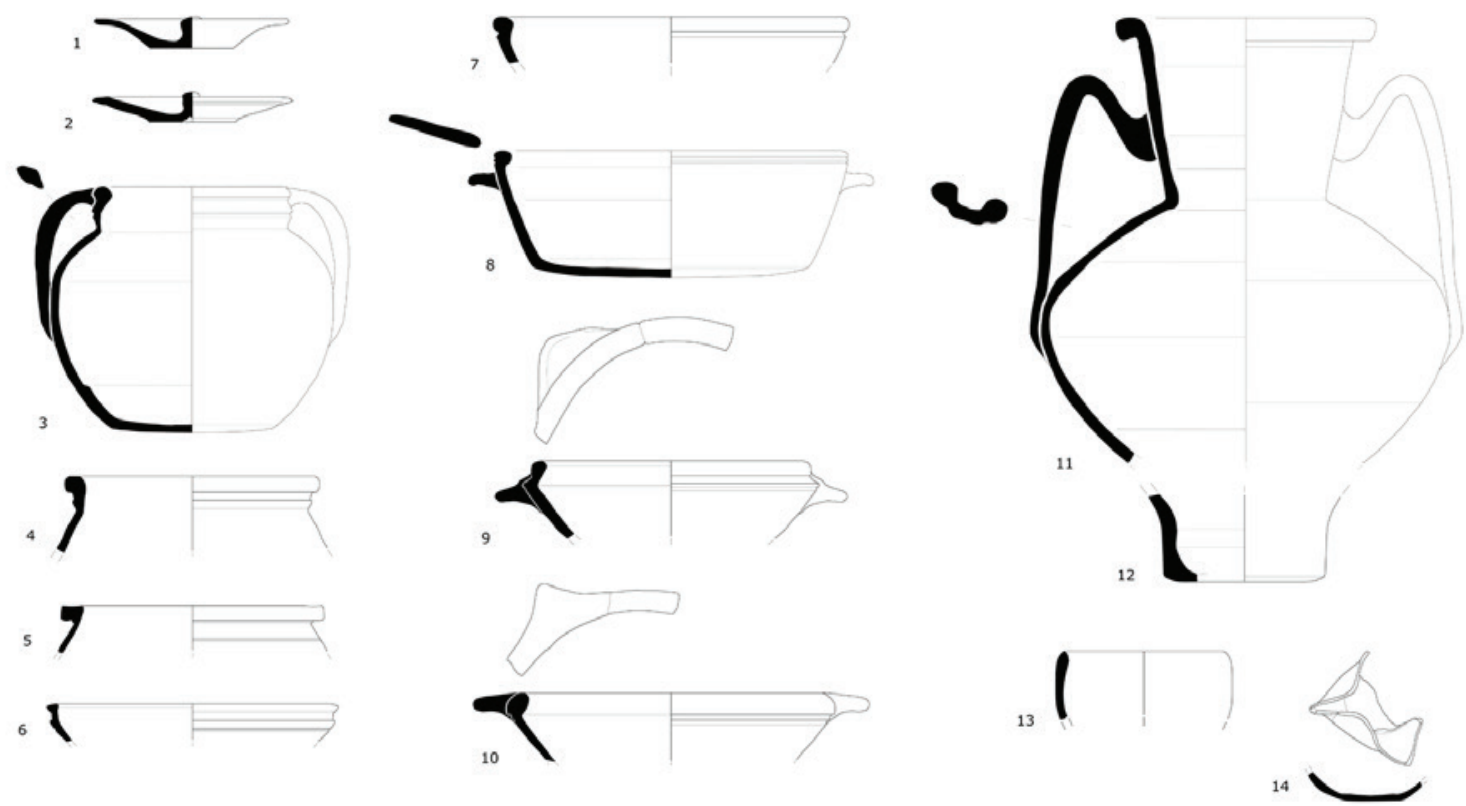

Fabrico F2
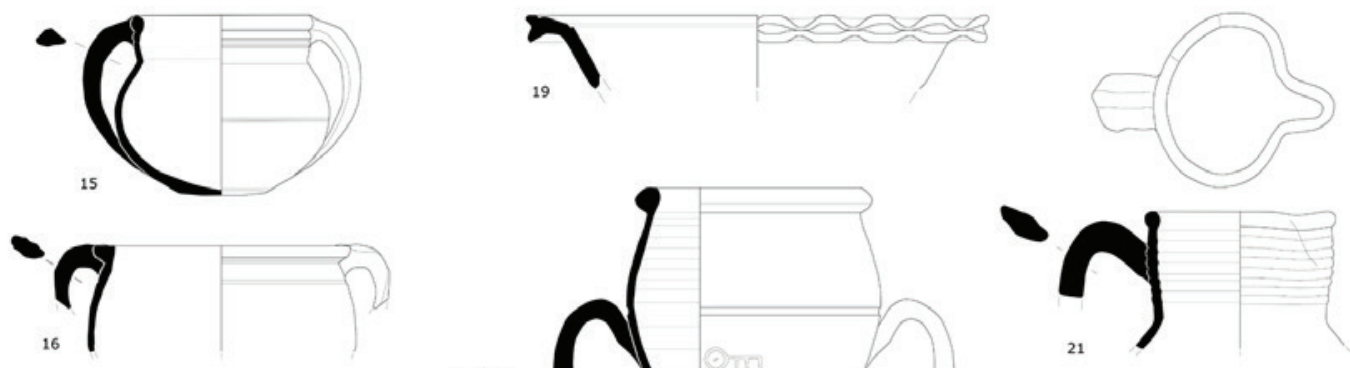

17 -
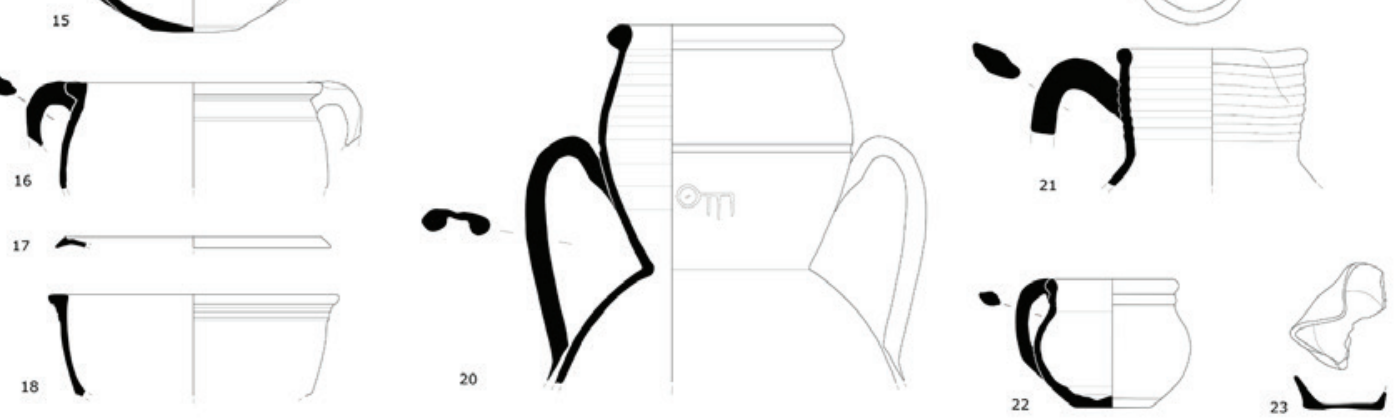

Figura 3 - Cerâmica fosca, possivelmente de produção local, registada no Ateneu Artístico Vilafranquense: testos nํㅗ 1-2 e 17; panelas $n^{\circ}$ 3-5 e 15-16; tigela $n^{\circ}$ 6; frigideira $n^{\circ}$ 7; tachos $n^{\circ}$ 8-10 e 18; cântaro $n^{\circ}$ 11-12 e 20-21; infusa $n^{\circ}$ 13; candeias $n^{\circ}{ }^{\circ} 14$ e 23; alguidar $n^{\circ}$ 19; púcaro $n^{\circ} 22$. 
=abrico B1

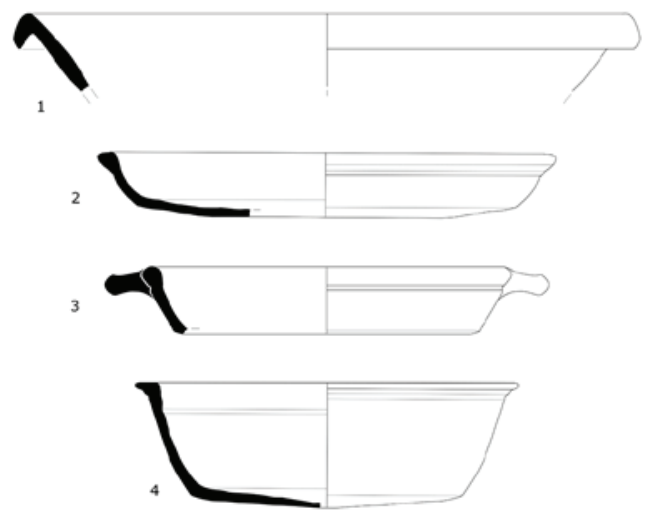

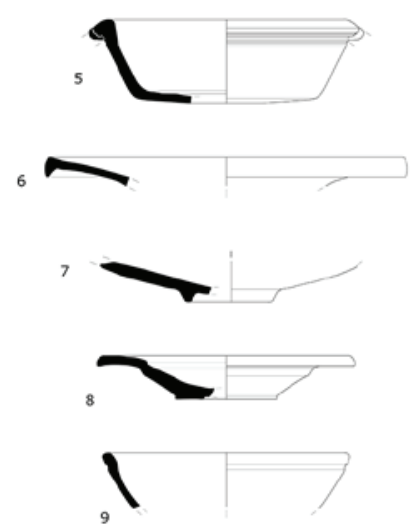

Fabrico B2

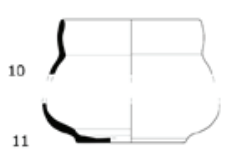

11

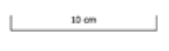

Figura 4 - Cerâmica brunida, possivelmente de produção local, registada no Ateneu Artístico Vilafranquense: alguidar nํㅜㄹ;

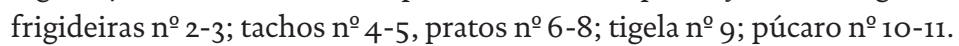





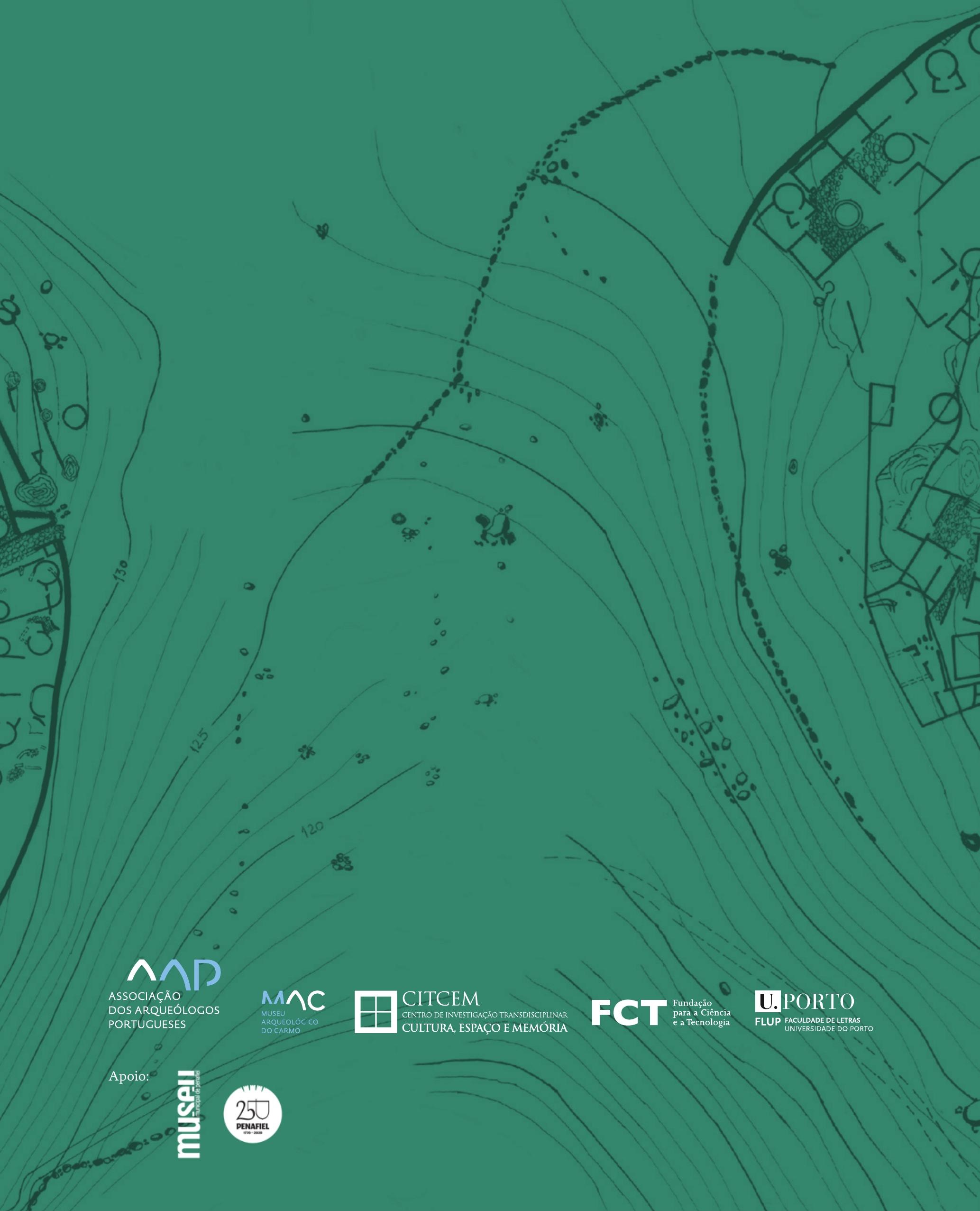

